\title{
WorkSim - a calibrated agent-based model of the labor market accounting for workers' stocks and gross flows
}

\author{
Olivier Goudet
}

Jean-Daniel Kant

January 26, 2017

\author{
Gérard Ballot
}

\begin{abstract}
This paper presents an agent-based model of the labor market. It simulates the market in the recent period at the aggregate level and at the level of the principal categories of labor, on the basis of the decisions of heterogeneous agents, firms and individuals, who interact. These decisions rely on individual computations of profits and utilities, although rationality is bounded in such a complex environment. The theoretical structure that underlies the decisions is the search concept. We apply this framework to the case of France in 2011. The model is at a scale of $1 / 4700$. It is fairly detailed on the institutions of the labor market that constrain the agents' decisions. Finally it is calibrated by a powerful algorithm to reproduce a large number of variables of interest. The calibrated model presents a consistent accounting system of the gross flows of the individuals between the main states, employment, distinguishing open ended contracts and fixed duration contracts, unemployment and inactivity. The simulation of the gross flows accounts enables us to analyze the patterns of mobility in a way that the observed statistics on gross flows, which are partial, cannot do. The model then characterizes the nature of the labor market under study, reproducing the high proportion of the fixed duration contracts in the hiring flows, and it points to a dualism of the French labor market.
\end{abstract}

\section{Introduction}

The model WorkSim is a novel tool of analysis for labor markets. The first objective of the model is to reproduce the gross flows between the important states: employment (distinguishing fixed term contracts and open ended contracts), unemployment and inactivity, and the ratios of individuals in these states. The novelty of the model is that it simulates the gross flows on the basis of the rational decisions of individual heterogeneous agents. The gross flow concept is crucial because each flow unit is caused by a decision that involves comparing idiosyncratic expected benefits and costs for the agent, and a flow unit will yield idiosyncratic benefits and costs for the agent and possibly other agent. It is not the case for transition based models that imply some time aggregation. Once the model is calibrated, the second objective is to characterize the nature of the labor market under study. This is done, first by examining the patterns of flows and stocks at the aggregate level and at the levels of different categories of labor, second by sensitivity experiments, modifying some exogenous parameters and variables such as the demand for the good. Finally the model once calibrated is a tool for experimenting labor market policies, including changes in the labor law. The multi-agent methodology is the perfect tool for such a research program, since it can model institutions precisely, and account for heterogeneity and individual interactions. Simulation results enable us to compute aggregate variables such as the flows and the stocks, and finally the individual careers and the main types of trajectories. 
However, the labor market is complex and this means that the modeling progresses only by steps. The present version is consistent as a stock-flow model and more detailed than other existing stock-flow models of the labor market, analytic, econometric, or multi-agent. The model builds on the experience of model ARTEMIS proposed by Ballot ((Ballot, 1981, 1988, 2002)) and a preliminary version of WorkSim by Lewkovicz and Kant (Lewkovicz \& Kant, 2008). ARTEMIS is the first multi-agent model to have modeled the gross flows between the three main states of the individuals, with the addition of on-the-job search as a state. This was also done within an institutional framework, notably with a temporary help firm, and firing costs. The accounting framework of stocks and flows allowed for a rigorous analysis of the competition between the different categories of labor. It threw some light on the effects of aggregate shocks or institutional change on the displacement or integration in open ended contracts of such categories as the young workers, female workers, low educated workers. The underlying hypothesis, that results confirm, is that these effects on the gross flows and stocks are highly non linear, or even non monotonic, and difficult to obtain through available econometric methods. For instance, a negative demand shock could possibly lower the unemployment rate of young non educated workers who would abandon participation, but raise unemployment for the other workers.

The version of WorkSim presented in this artical aims to analyze the French labor market in 2011. However the methodology we have developed will enable researchers to use it for other countries as well. WorkSim puts emphasis on one of the most important features of the French labor market that is the major role of the fixed term contracts, about $80 \%$ of the hires in 2011 . The present version is mainly devoted to the reproduction of the flows on the basis of our modeling of rational decisions. It then provides a first characterization of the patterns of flows of the different categories of workers, which is key for understanding the nature of a labor market, letting policy design for future work. Due to lack of space, we mainly restrict our economic analysis to the observation of a segmentation, and then throw a first light on the fundamental question: is the segmentation of a temporary or permanent nature for a generation of individuals?

This paper is organized as follows. Section 2 will present the theoretical framework and related models, section 3 will develop the model. Section 4 will deal with the calibration procedure, and section 5 the first characterization of the French labor market on the basis of the results. Section 6 concludes.

\section{Theoretical framework and state of the art}

\subsection{Extending Search Theory}

WorkSim like ARTEMIS is grounded in the concept of search (Phelps, 1970). It gives its intellectual coherence to the model, and the foundations for many of the decision rules. The search concept is necessary to distinguish the two states of "unemployed" and "inactive" on the basis of rational decisions of agents. There is indeed a flow from unemployment to inactivity, because the unemployment utility (expected gains from search minus time foregone) may become lower than the utility of inactivity (including welfare and free time). In that case, the individual stops search and becomes inactive. This is distinct from the fact that part of the inactive persons do not want to work because they have some other resources and value non-working time (caring for children). When the cost of search is introduced, the concept of search then also explains and it was the seminal idea of Stigler (1962) - that workers will sometimes prefer not to apply for a job and spend some more time unemployed to try to obtain a better job. They adopt a stopping rule that sets the minimum utility a job must offer to induce them to apply. These formalizations follow the definition of unemployment as a state in which workers act actively to find a 
job. This is a definition adopted by the International Labor Office (ILO), and the French National Statistical Institute (INSEE) in the Employement Survey, an enquiry that measures some of the variables the model wants to reproduce. In WorkSim the basic concept of search is extended in three directions, in order to build a general theory of mobility :

1. Search is done also by firms that symmetrically look for workers who are high in the productivity distribution. They prefer to keep a job vacant than hire a worker with a poor productivity. An optimal stopping rule taking the form of a minimum productivity requirement or hiring norm follows. A further possibility is that the addition of the costs of search and other costs (wages, expected firing costs...) makes the job unprofitable and it is suppressed.

2. The search calculus is extended to all voluntary decisions by workers such as quits to search and on-the-job search. Symmetrically, the firms take into account the search costs of replacement when they consider firing a worker, for insufficient productivity. Other relevant costs and benefits are also taken into account for firing, not renewing a fixed duration contract.... Finally the hiring decision is the result of the sequential decisions of the worker who applies and the firm which selects and hires. Moreover we do not use any matching function - unlike in the matching models such as the canonical model of Mortensen and Pissarides (Mortensen \& Pissarides, 1994) - as it is an aggregate artefact, likely not to be robust to large changes in the labor market, and with weaker microeconomic foundations than our double search decisions. The model definitely belongs to the pure search models, fully taking into account the heterogeneity of jobs and workers ${ }^{1}$.

(a) Our model integrates wage rigidities based on the realistic assumption that firms have often several jobs, which is not the case in the searchor matching models. Then equity requires a fixed wage structure between insiders'jobs. The model then allows for the differentiation between demand shocks and productivity shocks, while existing search models do not usually deal with this topic. WorkSim then contains some Keynesian features. Demand shocks explain part-time, economic dismissals, job creations and promotions in the model, while productivity changes explain dismissals on personal grounds, and some hires. This distinction has also some importance since the model deals only with the labor market, with no feedback on the goods market. The quantity demanded for the goods is exogenous.

However a major difference between WorkSim and the analytical search models relies on our utilization of the concept of Simon's bounded rationality to model the decisions (Simon, 1955). Two major arguments can be given:

1. First, dynamic programming algorithms used to solve the decision problem in analytical search theory cannot be used in a model in which heterogeneous agents move sequentially into many states over time and compete.

2. Second, according to bounded rationality theory, real agents have limited capacities in terms of computation and memory. They might therefore use simple rules, but a very important behavioral addition in our approach is that they can revise their decisions or even their rules thanks to learning and collecting information. This continuous learning is in fact very coherent with search theory. However, in order to compute equilibrium, analytical models assume perfect rationality and individuals have a lot of information such as the

\footnotetext{
${ }^{1}$ For evidence of the bias introduced by a matching function as a result of an employment policy, see (Neugart, 2008).
} 
true distribution of wages, and firms know the true distribution of productivities. By contrast, in WorkSim, we model "simple" decision rules - that comply with bounded rationality - and the learning processes.

\subsection{Related Agent-based models}

The contributions to the multi-agent literature on labor markets must also be assessed. This literature is thin but has a long history. Bergmann (2002) has developed a simple model of search by both sides of the market and obtained simultaneously vacant jobs and unemployment. Eliasson (1977) has built a Keynesian and Schumpeterian micro-to-macro model that treats only firms as individual agents but the number of workers in a firm can vary and unemployment is computed. It stresses poaching of labor by firms that grow and the wage competition that eliminates the firms that are not profitable. An extension by Ballot and Taymaz (2000) added human capital and the growing firms poach the more educated workers, enhancing a virtuous cycle of innovation and profit. ARTEMIS, the ancestor of WorkSim, stressed the different personnel management types to study segmentation. Some firms offer internal labor markets with a high selection at entry, but also training and promotion, and others offer lower wages, less selection, no promotion ("secondary jobs"). Moreover firms can recur to temporary help work, with very short contracts, but less selection than for internal labor markets. The model generates a temporary segmentation of the young workers. Then, a negative demand shock affects very differently the categories of labor, precluding the progressive integration of young workers in the internal labor markets. This leads to a permanent segmentation with serious life cycle consequences. WorkSim brings many improvements over ARTEMIS. It replaces the "secondary" jobs by the fixed duration contract with the main legal specificities that apply to them in 2011. It also models the accumulation of several types of human capital, and considers that workers have an idiosyncratic component in productivity so that the employers learn - but never know perfectly - the productivity of their employees. This is a source of personal dismissals, while in ARTEMIS the workers when hired became equally productive through an adapted training. Moreover the model is calibrated by a powerful algorithm to fit year 2011, while ARTEMIS was calibrated by hand to fit the evolution 1972-75. In WorkSim, a simulation is repeated 200 times to average out the stochastic effects while ARTEMIS could not - for computational cost reasons - be tested with more that a few runs. In order to focus precisely on the role of fixed duration contracts, we do not integrate - at this time - the temporary help jobs modeled in ARTEMIS.

The years 2000 have mainly seen the construction of multi-agents models aiming at theoretical research, such as introducing networks on the labor market, i.e. the role of social relations in the hiring process, a way to go beyond random search that is relevant in some contexts (Tassier \& Menczer, 2001), and the study of the robustness of aggregate relations such as the Beveridge curve that describes the negative relationship between vacancies and unemployment, if one starts bottom up by modeling the firms and individuals decisions (Richiardi, 2006). However,

one model has tried to model the French labor markets with some of its specificities. Barlet et al. (2009) simulate the French labor market for year 2006. They distinguish individuals and jobs but not firms as such although there is a labor demand side, with creations and destructions of jobs based on a desired margin and demand. Fixed duration and open ended contracts are also distinguished. The flows are obtained from transition rates, often exogenous, and the dismissals are determined by the destruction of jobs exclusively (and not by insufficient productivity). The model is calibrated using an indirect inference method to fit a set of real data, and is then used to study the effects of the rise of the minimum wage and a lowering of the social charges on the firms. However, there are no inactive individuals in their model, hiring is performed through 
an aggregated matching function, quits are exogenous, and the terminations of fixed duration contracts are random. One another important difference with ARTEMIS and WorkSim is that the period is the year and therefore the gross flows are not reproduced, which prevents a fine analysis of fixed duration contracts and unemployment spell durations.

The version of WorkSim (in the line of ARTEMIS) presented here then goes beyond the existing multi-agent literature on the labor markets in three directions, as the following sections will show:

1. It is the only model to be grounded in a double stock-flow accounting, one for the individuals, one for the jobs, and all the flows between the stocks considered are simulated. This accounting is the equivalent of the financial stock-flow accounting for ACE macroeconomic models, a guarantee of consistency. It also allows for a easy description of the labor market dynamics at the aggregate and at any disaggregation level of interest, and the highlighting of the competition between categories of labor (young, adults, seniors....) with possible crowding out effects.

2. It models the institutions and the labor law at their level of direct impact (the microeconomic level), since they are rules of the game that agents know and take into account in their decisions. The diverse forms of labor contracts, with very important differences, are probably the major feature of the French labor market, and they are at the heart of the model, since they modify the flows ${ }^{2}$.

3. Most of the gross flows are generated by rational decisions based on an enlarged search theory, and the effects of shocks we will study then integrate the agents responses and interactions within the rules of the game and the accounting constraints. Our multi-agent model then provides a tool to explore rigorously the complex system constituted by the labor market.

\section{Model Description}

\subsection{The agents in WorkSim}

In WorkSim, the agents are heterogeneous. They have specific attributes determined once and for all at their creation and internal variables which evolve all along the simulation. The agents attributes and variables are shown in Appendix A. There are two types of agents: Private Firms and Individuals. At its creation, each firm starts with at least one worker to run the company, denoted in this paper as the managing director. The Individuals are grouped in households and the simulation evolves in a closed population. The individuals can marry each other, have children, break up, and therefore the decisions of one member of the household may have an impact on the other members.

The agents under 15 or over 65 years belong to these household but are not instantiated as full agents and do not take decisions in the model. However, these non-instantiated agents indirectly participate through the economic decisions of the other members of the household (eg. the number of dependent children is taken into account in decisions of transition to inactivity, the retirement pension is included in household income). The individuals under 15 years become full agents in the model at the age of 15, and some remain in the school system while

\footnotetext{
${ }^{2}$ The diversity of contracts exists in many other countries and the model could be adapted to simulate other labor markets.
} 
others enter the labor market. 


\subsection{Environment}

In addition to these agents. the model uses three artifacts $^{3}$ :

- JobAds, which receives job offers from the firms and job applications from the job seekers. Dissemination of information, however, is based on the job search process described in more detail below (see sections 3.6.4 and 3.7), according to the principles of the theory of search.

- a "statistical institute" that calculates all the statistics from a simulation model. and disseminates some information (e.g. tension on the labor market). The information is imperfect for agents, and we specify what information is being broadcasted.

- a Public Sector that recruits (exogenously) employees, collects payroll taxes on businesses.

\subsection{Institutional Framework}

Moreover, it also includes one institutional module. One distinctive feature of the WorkSim model is to integrate a fairly complete and flexible institutional framework that includes (1) the necessary elements of the French labor Law, including two types of contract: fixed duration contracts $(F D C)^{4}$ and open ended contracts $(O E C),{ }^{5}$ dismissals on personal and on economic grounds, redundancy payments, ... ). and (2) government decisions (minimum wages, welfare benefits, ...). The parameters of the institutional framework are shown in Appendix B.

\subsection{Key Economical Computations in the WorkSim Model}

Before detailing the behaviors of the our agents in the model, let us describe some key economic computations in WorkSim.

\subsubsection{Benefit of the firm}

Firm Income - The only production factor is the labor, like in many labor market models. There is one non-storable good, and each firm produces a certain amount of its own variety of this good. Each firm responds to a quantity demanded of this good $D_{j, t}$, defined as its share of the total quantity of the good demanded, share that fluctuates randomly according to a random walk. Total quantity demanded $D^{\text {tot }}$ is held constant because we aim to study our labor market in a steady state. Exogenous shocks on this total demand will be introduced in a sensitivity analysis to study the response of the main variables. In order to illustrate the coherence of a constant total demand with stochastic shocks on firms own demand, we can for instance look at a goods market with horizontal differentiation, where firms undergo stochastic variations of consumers' preferences for their own variety. Price adjustments have a cost, and then firms dare not modify the price. Since the unit costs are not too dissimilar, we can then set a unique exogenous price

\footnotetext{
${ }^{3}$ Artifacts in multi-agent systems are the passive (non-proactive) entities providing the services and functions that make individual agents work together Omicini et al. (2008), and must be differed from proactive autonomous entities like the individuals or the firms.

${ }^{4}$ Main FDC Features: maximum duration of 18 months with the possibility to go to 24 months in some cases, including the possibility to be renewed once, a small probationary period and allowance at the end of the contract: $10 \%$ of total gross salary. Cannot be broken without heavy penalties (paying the remaining salary part).

${ }^{5}$ Main OEC Features: no duration limit, probationary period, no firing costs for the first year, no termination costs if quitting, variable firing costs when firing.
} 
(Salop, 1979). Firms that make losses for some time fail. The firm production is linear additive in terms of the productions of the different workers, given that employees work either full time or part time.

A firm is composed of a manager and employees of 3 different occupation levels $(1=$ blue collar or employee, 2 = middle level job, 3 = executive ).

Each firm has a specific organization and needs labor for each occupation level $q$ :

$$
D_{j, q, t}=D_{j, t} \times \psi_{j, q}
$$

with $\psi_{j, q}$ the share of demand of the firm $j$ allocated to the occupation level $q$. At the creation of a firm, these shares are randomly drawn from a standard normal distribution with a mean $\mu_{\Psi_{q}}$, which depends on the occupation level of the job, and a standard deviation $\sigma_{\psi}$.

At each step of our simulation - one week in the reality ${ }^{6}$, we assume that each occupation $q$ in the firm $j$ cannot contribute more than its demand $D_{j, q, t}$ or its production capacity $Q_{j, q, t}^{e f f}$ (computed as the sum of the production of all these $n_{j, q}$ employees). The income of the firm $j$ at time $t$ is given by:

$$
R_{j, t}^{e f f}=P \times \sum_{q=1}^{3} \min \left(Q_{j, q, t}^{e f f}, D_{j, q, t}\right)
$$

Firm costs - The regular global cost of the firm is:

$$
C_{j, t}^{e f f}=\sum_{i=1}^{n_{j}} C_{i, j, t}^{e f f}
$$

where $C_{i, j, t}^{e f f}$ is the effective salary cost of the employee $i$ in the firm $j$ at time $t$ and $n_{j}$ the total number of employees. There are additional costs $C_{j, t}^{a d d}$ that include training costs, firing costs and vacancy costs.

Benefit - The profit of the firm at time $t$ is given by:

$$
\Phi_{j, t}^{e f f}=R_{j, t}^{e f f}-C_{j, t}^{e f f}-C_{j, t}^{a d d}
$$

This profit is stored in the history of the firm in order to perform a quarterly balance (cf. section 3.6.2).

\subsubsection{Determination of firm production $Q_{j, q, t}^{e f f}$}

There is a base production attached to each job, and the employee's characteristics will modulate its value to determine the effective production. Moreover, the employer has only an imperfect and evolving information on individual production ${ }^{7}$.

\footnotetext{
${ }^{6}$ One week is necessary to account for very short term contracts that are common in France.

${ }^{7}$ Compared with the previous version of WorkSim (Lewkovicz \& Kant, 2008), the present version introduces experience factors and imperfect information.
} 
Base production per occupation level - In the firm an employee occupies an individualized job $p$, notably characterized by a occupation level $q$, but also by the nature of the job contract, the expected duration of this contract, the work time per period (full-time or part-time job).

The weekly base production for a job $p$ at occupation level $q$ in firm $j$ is randomly drawn within bounds from a normal distribution with a mean $\mu_{q}$, which depends on the occupation level of the job, and a standard deviation $\sigma_{q}$. The base production of a worker (for full time) reflects the technology embodied in the equipment used by the workers in the occupation q. The technology is not explicitly modeled and it is assumed to be different between firms but identical for all jobs in the same occupation in a given firm. Moreover there is presently no technical progress in the model so that the base technologies are fixed variables for a firm, and the base production is drawn from a distribution when the firm is created :

$$
\left.Q_{j, q}^{\text {base }}=\operatorname{Max}\left(0,\left(\mu_{q} \times \mathcal{N}\left(1, \sigma_{q}\right)\right)\right) \times N b H \text { oursPerWeekRatio } \text { contract }_{p}\right)
$$

where $N b$ HoursPerWeekRatio(contract c $_{\text {) }}$ is a coefficient equals to 1 if the contract of the job is a full-time job (35 hours per week) and equals to $\frac{1}{2}$ if the contract is a part-time job.

Effective production - The effective production of an individual $\mathrm{i}$ at job $\mathrm{p}$ in firm $\mathrm{j}$ is given by :

$$
Q_{i, j, q, t}^{e f f}=Q_{j, q}^{\text {base }} \times C \operatorname{Prod}_{i} \times F_{\beta_{q}}\left(C H_{i, t}^{\text {general }}+C H_{i, q, t}^{\text {occ }}\right) \times F_{\lambda}\left(C H_{i, p, t}^{\text {spec }}\right)
$$

The $F_{y}$ functions are given by: $F_{y}(x)=1+y \times x$, and $\beta_{q}$ a positive exogenous parameter.

The effective production is based on four complementary factors : (1) the base production in the job, (2) the core productivity of the employee, (3) the general human capital of the employee, and (4) the specific human capital in the job she holds ${ }^{8}$ :

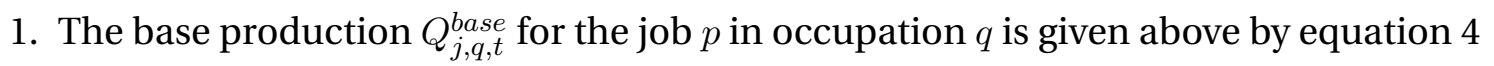

2. $\operatorname{CProd}_{i}$ is the core productivity of the individual i. $\operatorname{CProd}_{i} \sim \operatorname{Max}\left(0, \mathcal{N}\left(1, \sigma_{\text {Prod }}\right)\right)$ with standard deviation $\sigma_{\text {Prod }}$. It encodes the initial skills and motivations of the individual.

3. $C H_{i, t}^{\text {general }}$ is the general human capital production factor,

$C H_{i, t}^{\text {general }}$ is the stock of general human capital detained by individual $i$ at time $t$, and equals the general work experience Experience $i, t$.

4. $C H_{i, q, t}^{o c c}$ is the occupational human capital production factor, with $\beta_{q}$ a positive exogenous parameter.

$C H_{i, q, t}^{o c c}$ is the stock of human capital related to occupation level $q$ and detained by individual $i$ at time $t$. It equals the work experience obtained in the occupational level Experience $_{i, q, t}$.

5. $F_{\lambda}\left(C H_{i, p, t}^{s p e c}\right)$ is the job-specific production factor. $\lambda$ an exogenous parameter. $C H_{i, p, t}^{\text {spec }}$ is the specific human capital of an individual $i$ in the occupation $q$ at the job $p$ in the firm $j$ and is given by:

$$
C H_{i, p, t}^{\text {spec }}=\text { Senior }_{i, p, t}^{\text {spec }}
$$

where Senior $_{i, p, t}^{\text {spec }}$ is the seniority in number of periods of individual i at job $\mathrm{p}$ in firm j. Notice that if the individual receives a promotion and changes her occupation level in the

\footnotetext{
${ }^{8}$ This complementariness is justified by several economic studies. The complementarity in terms of performance between a technological level of a job (related to implicit physical capital associated) and a level of human capital used is a common accepted fact (Leiponen, 2005), even if it should be qualified. The complementarity between general human capital and specific human capital has the following theoretical basis: the general human capital of an individual allows him to better utilize her specific knowledge (Ballot \& Taymaz, 1997; Acemoglu \& Pischke, 1999).
} 
company, the seniority will be reset to 0 . The specific human capital in the original definition of Becker (1975) represents the skills acquired by an individual in a firm and only useful in this firm. However, the seniority factor in a firm appears to have little impact (at least on wages) in France since the 90s (Beffy et al., 2006). In our model, we distinguish jobs by occupation and each occupation allows to acquire skills (technological and social) specific to this occupation but transferable between firms ${ }^{9}$

Each period spent in employment, Experience ${ }_{i, t}$ and Experience $_{i, q, t}$ increase $^{10}$ by 1 but are reduced by a percentage - respectively $\operatorname{PrLoss} X P$ and $\operatorname{PrLoss} X P_{q}$ - in each period spent out of employment ${ }^{11}$. This decrease will start only after 6 months after leaving employment.

Employee production estimation - One key theoretical options of WorkSim model is that an employer never knows perfectly the production of an employee. This hypothesis is in the line of Jovanovic (Jovanovic, October 1979), and was the basis of important developments in labor economics. This hypothesis has multiple potential effects on the functioning of the labor market. We assume that the company does not have any a priori knowledge about the precise levels of real productivity for each of its employees. Therefore, it is only able to assess a level of estimated productivity:

$$
Q_{i, j, q, t}^{\text {estimated }} \sim \operatorname{Max}\left(0, \mathcal{N}\left(Q_{i, j, q, t}^{\text {eff }}, \sigma_{i, j, q, t}\right)\right)
$$

This amount $Q_{i, j, q, t}^{\text {estimated }}$ is drawn from this distribution when the employee is hired, and also at each employee evaluation. $\sigma_{i, j, q, t}$ represents the degree of uncertainty of the company in the evaluation of its employees. It decreases in the seniority of the employee in the firm at her level of occupation (informal learning by the employer) and in the number of times she has been evaluated by the firm (formal learning that takes place on specific occasion such as the end of probationary period, or the end of a FDC if a transformation into an OEC is considered):

$$
\sigma_{i, j, q, t}=\operatorname{Max}\left(0, \sigma_{0} \times\left(1-\delta_{\sigma} \times \operatorname{Senior}_{i, j, q, t}^{\text {spec }}-\eta_{\sigma} \times \# \operatorname{Eval}_{i, j, q, t}\right)\right)
$$

with $\sigma_{0}, \delta_{\sigma}$ and $\eta_{\sigma}$, three exogenous parameters ${ }^{12}$.

\subsubsection{Determination of firm costs $C_{i, j, t}^{e f f}$}

Base salary The weekly base salary for a job $p$ at occupation level $q$ in firm $j$ is written $S_{j, q}^{b a s e}$. It is determined from the base production in the job:

$$
S_{j, q}^{b a s e}=Q_{j, q}^{\text {base }} \times P \times\left(1-\zeta_{j}\right)
$$

\footnotetext{
${ }^{9}$ We have made the choice to discard the notion of firm human specific capital by creating instead two new types of human capitals. The first is the occupation human capital, which corresponds to the professional skills acquired in the educational system and subsequent experience acquired in a given occupation level. This type of human capital is obviously important and distinct from work experience since entering the labor market in the model (see Gibbons et al. (Gibbons et al., 2005), Kambourov \& Manovskii (Kambourov \& Manovskii, 2009) for evidence). In the model it is specific to a broad aggregate of occupations $q$, but it could be extended to more finely defined professions or crafts. The second is the job specific human capital. It covers possibly some required training given when entering the job but in any case the experience by learning on the job. It is assumed to be so specific that it will not have any use in other jobs. It notably contains some social skills specific to the job.

${ }^{10}$ These increases in productivity corresponds to the learning by doing phenomena highlighted by Arrow (1962) and represent increases in productivity without training costs for the firm.

${ }^{11}$ This is to model the impact of skills forgotten due to a too long period of unemployment or inactivity.

${ }^{12}$ Note that when the firm consists only of its managing director or the managing director with one employee, the firm knows its global production $Q_{j, t}$ and does not have any doubt on the effective productions; therefore $\sigma_{i, j, q, p, t}=0$.
} 
with $\mathrm{P}$ the exogenous price of the (unique) good and $\forall j, \zeta=\zeta$, an exogenous parameter that represents the share of the sales revenue (of base production here but also of the sales of effective production below) kept by the firm in order to pay intermediate consumptions, payroll charges, taxes, interests, investments, dividends, etc.. It reflects the balance of power between workers and employers, the size of public services in the society and the technology among the principal determinants. Although it differs in the real world between firms because the expenditures differ between firms, we will assume it is uniform since the model does not focus on the determinants not related to the human resources management.

Weekly starting salary The starting net salary $S_{i, j, q, t=h i r i n g}^{e f f}$ of an employee $i$ in firm $j$ at level of occupation $q$ at time $t=$ hiring is given by:

$$
S_{i, j, q, t=h i r i n g}^{e f f}=\operatorname{Max}\left(S M I C, S_{j, q}^{\text {base }} \times F_{\beta_{q}}\left(C H_{i, t=h \text { iring }}^{\text {general }}+C H_{i, q, t=h \text { hiring }}^{\text {occ }}\right) \times G\left(U_{t=\text { publish }}\right)\right)
$$

SMIC ${ }^{13}$ is the minimum hourly wage in France, net of the employee's contribution to social security, multiplied by the number of hours worked on the job. The starting salary is the base salary of the job modulated by the general and occupational human capitals of the employee. Due to important considerations of equity in terms of human resource management (e.g. (Adams, 1963)), the employer cannot discriminate between employees who have the same experience. A feeling of unfairness could generate decreases in effort and productivity for the employees who feel unequally treated (efficiency wage concept) ${ }^{14}$.

A final factor affecting wages is the global unemployment rate $U_{t=p u b l i s h}$ at the time of publication of the job offer by the firm.

We consider that the relation $\mathrm{G}$ is isoelastic, according to the literature on the wage curve (Blanchflower \& Oswald, 1994), and take $G(x)=k \times x^{\omega}$, where $\omega$ is an exogenous parameter, set at its standard value of -0.1 , and $k=\left(\frac{1}{U_{r e f}}\right)^{\omega}$. $U_{\text {ref }}$ is set as the global unemployment rate for the reference year we study $\left(U_{r e f}=0.092\right.$ in 2011).

Annual increase of the weekly wage The weekly salary of employee $i$ in firm $j$ is reviewed annually at her birthday date of her arrival in the company according to the equation:

$$
S_{i, j, q, t}^{e f f}=\operatorname{Max}\left(S M I C, S_{j, q}^{\text {base }} \times F_{\beta_{q}}\left(C H_{i, t}^{\text {general }}+C H_{i, q, t}^{\text {occ }}\right) \times F_{\lambda_{q}^{*}}\left(C H_{i, j, q, t}^{\text {spec }}\right) \times G\left(U_{t=\text { publish }}\right)\right)
$$

with $F_{\lambda_{q}^{*}}\left(C H_{i, j, q, t}^{\text {spec }}\right)$, the productivity gains factor related to her experience in the job that affects her salary. It is assumed here that, following the consensual principals of specific human capital theory, the company gives to the worker only a part of the productivity gains related to specific human capital, hence $\lambda_{q}^{*}<\lambda_{q}$. However, according to the insiders-outsiders theory, the employee's salary is not affected by changes in the state of the labor market after hiring (the factor $\mathrm{G}(\mathrm{U})$ remains the same as it was at the time of publishing the vacancy). Some rigidity in search models is necessary to obtain variations in unemployment during the cycle and Pissarides (Pissarides, 2009) has argued that hiring wages are flexible and current contracts rigid, a double hy-

\footnotetext{
${ }^{13}$ as for "Salaire minimum interprofessionnel de croissance". In 2011, the monthly net minimum wage for a fulltime job was $1072 €$.

${ }^{14}$ Moreover, in terms of theoretical consistency, it is necessary to choose a posted salary and not a salary negotiated on the basis of the match value. The matching theory usually chooses the latter, but the search theory involves the assumption of a distribution of salaries offered by companies, which leads job seekers to evaluate jobs and apply for them (or not).
} 
pothesis which fits the wage curve and the insiders-outsiders theory, and that we can implement easily since the wages are individualized ${ }^{15}$.

Effective cost of an employee $C_{i, j, q, t}^{e f f}$ The effective cost of an employee $C_{i, j, q, t}^{e f f}$ include her salary $S_{i, j, q, t}^{e f f}$ and payroll charges .

$$
C_{i, j, q, t}^{e f f}=S_{i, j, q, t}^{e f f} \times(1+\operatorname{PrCharge})
$$

PrCharge is the ratio of payroll charges to net salary. It includes both the employee's and the employer's charges.

\subsection{Simulation cycle in the WorSim Model}

The simulation cycle includes four main steps, as shown in Figure 1 below:

1. Firm decisions: contracts and vacancies management, evaluations, job creation / destruction

2. Individual decisions: labor market entrances and exits, job search

3. Firm decisions: applications and promotions management

4. Demography: household dynamics, retirements, aging

The length of one period in the simulation cycle corresponds to one week in the real world, in order to take into account the many very short term contracts that are found in the French labor market, $46 \%$ of all hires are on FDC that last one week or less in 2010 (Berche et al., 2011). Moreover, when statistics are needed, we took as a reference year 2011, the most recent year for which we could find the complete statistical data and sources.

\subsection{Firm decisions}

In each period and for each occupation level, each firm has to create new jobs or destroy existing ones, depending on an exogenous demand. Then, it manages its employees through evaluation, possibly dismissals, and manages the fixed duration contracts. For each occupation level q, we define the demand margin $G_{j, q, t}=D_{j, q, t}-\left(Q_{j, q, t}^{e f f}+Q_{j, q, t}^{*}\right)$, as the difference between:

- the amount of good demanded to the firm $D_{j, q, t}$, which varies stochastically among firms, and

- the sum of the current total effective production of the firm $Q_{j, q, t}$ and the current expected production of vacant jobs (to be filled) of the firm $Q_{j, q, t}^{*}$

\subsubsection{Job creations (step 1 in Figure 1)}

When $G_{j, q, t}>D T h$, where $D T h \geq 0$ is a fixed parameter, the firm considers whether to create a new job to be filled. The characteristics of the job to be created are based on two exogenous probabilities (calibrated, see values in Appendix C) :

\footnotetext{
${ }^{15}$ See e.g. (Lindbeck \& Snower, 1988). Note that very strong recessions like the 2008 recession might justify to qualify this hypothesis at the level of some firms.
} 


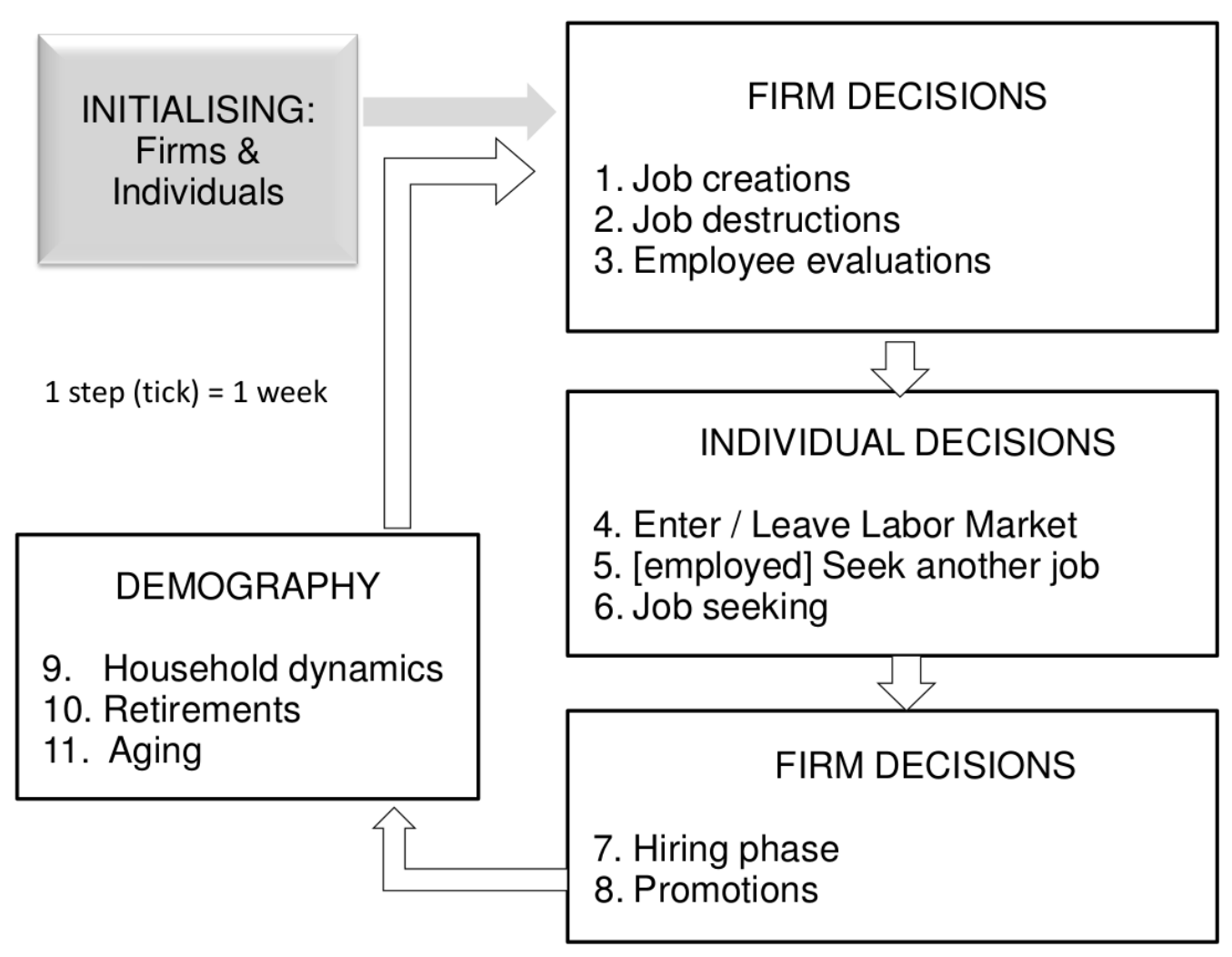

Figure 1: The simulation cycle in WorkSim

1. The first sets the choice between creating a FDC and an OEC. This decision is based on exogenous probabilities identical for all firms. If a FDC is drawn, its duration will be set by another drawing. The durations considered for the FDC are: 1 week, 1, 2, 6, 12 or 24 months.

2. The second one decidess whether the job should be full-time or part time.

Before definitely creating job $p$ of occupation $q$, the company estimates its expected profit per period from the expected revenue $R_{q, j, t}^{\text {expected }}$ and costs $C_{q, j, t}^{\text {expected }}: \Phi_{q, j, t}^{\text {expected }}=R_{q, j, t}^{\text {expected }}-C_{q, j, t}^{\text {expected }}$.

The expected revenue from this productivity is given by:

$$
R_{q, j, t}^{\text {expected }}=P \times \min \left(G_{j, q, t}, Q_{A v g, q}^{e s t i m}\right)
$$

with $G_{j, q, t}$ the demand margin and $Q_{A v g}^{e s t i m}$ is the average of all the productivity estimates for the individuals that will be evaluated during the prospecting phase.

The cost per period is a function of the wage but also includes a potential cost of a contract breach. This cost will differ with the nature of the contract (FDC or OEC) :

$$
C_{q, j, t}^{\text {expected }}=S_{A v g}^{\text {estim }} \times(1+\operatorname{PrCharge})+C P \text { osVac } c_{q, t}^{\text {expected }}+C E n d_{q, t}^{\text {expected }}
$$

where $S_{A v g}^{\text {estim }}$ is the average of all the net wage estimates for the individuals that will be evaluated during the prospecting phase. $C P$ osVac $c_{q}^{\text {expected }}$ and $C E n d_{q, t}^{\text {expected }}$ are respectively the expected total cost of a vacancy and the expected total end cost of the contract (short-term contract 
bonus, firing cost,...) amortized over the expected duration of the contract. These costs are estimated by learning. As generally found in search theory, the vacancy cost will impact the hiring norm (though the expected profit, see section 3.6.4 below).

Thus, if its current expected profit $\Phi_{q, j, t}^{\text {expected }}>0$, the company publishes a job offer at the wage $S_{j, q, t}^{b a s e}$.

\subsubsection{Job destruction (step 2 in Figure 1)}

By contrast, when there is a significant reduction in its demand in one occupation level (in our model, this is when $G_{j, q, t}<-D T h$ ), the firm reacts in the short term by removing its vacancies. In the medium run (on a quarterly basis), if this low cost adjustment is not sufficient, the firm considers the possibility to dismiss workers (see 3.6.3 below).

Moreover, independently of the demand level, the vacancies that remain unfilled and have a vacancy duration greater than a fixed threshold - a parameter that will differ for FDC and OEC are destroyed.

Short-term adjustment: vacancy removals In each period, when $G_{j, q, t}<-D T h$. the company randomly draws one of its vacancies and evaluates the interest to keep it or not. To do this, the company recalculates the demand margin $G_{j, q, t}^{\prime}$ it would have without this vacancy, and reassesses its interest it would have to create the job now. If this time $\Phi_{q, j, t}^{\text {expected }}<0$, the company removes the vacancy and $G_{j, q, t}$ is increased by $Q_{j, q, t}^{\text {expected }}$. This process is repeated for all the remaining vacancies as long as overproduction remains (i.e. as long as $G_{j, q, t}<-D T h$ and there are still vacancies to be removed).

Medium-term adjustments: economic dismissals An evaluation of the financial viability of the company is performed on a quarterly basis (12 periods in the simulation). The first date of the balance sheet is drawn randomly, then this financial reporting occurs every three months from this date. The company calculates its quarterly return that is computed as the ratio of the quarterly profit over the total labor $\operatorname{cost}^{16}$. If this return falls below a certain profitability threshold (a fixed parameter $P T$, that will be calibrated and can be negative), the firm engages an economic dismissal procedure:

- All remaining vacancies are removed.

- The company dismisses a number of employees, drawn randomly. The company cannot set the ranking according to the estimation of the profit of the individual employees, even though it has some estimate, since the French labor law and collective agreements set several criteria of ranking that must be respected first. Moreover, the criteria differ between collective agreements, and we considered this ranking process to be too complex to be modeled. The number of employees dismissed is chosen as the minimum number of persons to fire in order to get a return above the profitability threshold.

If a company has no employee anymore, and if the managing director left alone does not make a sufficient return, the firm is considered to be bankrupt and is removed from the simulation. The managing director becomes unemployed. However, we want to keep the number of firms constant since we aim for a steady state. Hence, when a bankruptcy has occurred, we randomly

\footnotetext{
${ }^{16}$ The labor cost represents here the capital funds the firm has to pay in advance. Hence, the return is the ratio of the profit over this capital.
} 
select an active agent in the simulation to create a new firm and manage it. To keep the number of contracts types low, we assume that she will work under an OEC contract and be the only producer in the firm (until she starts to recruit).

\subsubsection{Employee evaluations (step 3 in Figure 1)}

In each period, the firm examines if some employees have to be evaluated. This individual evaluation may occur:

- At the end of the probationary period for FDC and OEC;

- At the end of FDC contract to decide if it should be renewed ;

- At the end of FDC contract, if the transformation of FDC to OEC is to be considered ;

- Every year, at the anniversary date of the contract, for each FDC or OEC employee.

In order to decide whether the employee should be kept, the firm calculates a profit for each scenario:

- First scenario: the firm keeps the employee. The company computes the demand margin it gets without this employee, and evaluates as in section 3.6.1 the interest it would now have to create this job. Thanks to learning, the firm knows better this time the employee's actual productivity.

- Second scenario: the firm does not keep the employee (dismissal on personal ground):

1. If the employee is under OEC, the firm evaluates the dismissal costs (specific to a dismissal on personal ground) ;

2. The company computes the potential profit given by a new employee, who would be recruited to replace the fired employee (with the same contract and the same level of occupation).

The firm compares the total profits associated with each scenario. If the firm chooses to dismiss the employee (end of probationary period, end of FDC contract, OEC firing on personal ground), it publishes a new job add to recruit a new employee at the same level of occupation.

\subsubsection{Hiring phase and promotions (step 7-8 in Figure 1)}

If workers are distributed according to productivity, search theory shows that the firm should set an optimal reservation productivity or profit, under which it rejects the candidates. This reservation profit is based on the probability to attract candidates, the distribution of the discounted values of the productivities of these candidates over the expected duration of the job, and the cost of the vacancy per period, but this list is not exhaustive. A firm will prefer to wait one more period than recruiting if all current candidates are below this reservation productivity. The determination of the optimal reservation profit is symmetric to the worker's search recursive model under fixed wages. ${ }^{17}$ Since rationality is bounded, and the productivity distribution unknown,

\footnotetext{
${ }^{17}$ Very little attention has been brought to optimal search theory by firms, certainly because matching theory has replaced the detailed decision based approach of search theory that could consider heterogeneous firms by a representative agent approach. Pissarides (Pissarides, 1976, p.37-41) is an exception and computes the optimal reservation productivity -that he calls recruitment standard- for a fixed wage. He also shows that if the firms had very flexible wages, they would use that tool rather than a recruitment standard, but we do not consider that firms can change their wage offer to respond to their idiosyncratic recruiting problems.
} 
we define a hiring norm that replicates the main results from search theory. The hiring norm of the firm is given by:

$$
\operatorname{HiringNorm}_{j, q, p, t}=\mathrm{N}_{1} \Phi_{j, q, t}^{A v g}\left(1+\mathrm{N}_{2} \frac{\Phi_{j, q, t}^{M a x}}{\Phi_{j, q, t}^{M i n}}\right) \frac{N\left(d_{p}\right)}{H\left(I T E N S_{t}\right)}
$$

with $N_{1}, N_{2}$ two exogenous parameters. The firm is assumed to know a small sample of candidates without cost (by its former presence on the labor market), but not large enough to estimate the parameters of the productivity distribution, a demanding and complex process. It calculates the expected profits, and for the positive ones, the company stores the average $\Phi_{j, q, t}^{A v g}$, the maximum of these profits, $\Phi_{j, q, t}^{M a x}$ and the minimum $\Phi_{j, q, t}^{M i n}$. A first result of search theory is that firms prefer distributions with a higher profit mean and $\Phi_{j, q, t}^{A v g}$ raises their hiring norm. A second result of search theory is that firms prefer more variance in the distribution since there are more high productivity workers. An increase in the mean preserving variance raises the hiring norm (Pissarides, 1990, p.97). We formalize this result by a bounded rationality rule in which the relative range of the productivities $\mathrm{N}_{2} \frac{\Phi^{M a x}}{\Phi^{M i n}}$ raises the hiring norm. A third result is that the norm is an increasing function of the duration of the contract $d_{p}$ proposed for the job through the factor $N\left(d_{p}\right)$ : it has a minimum of $N_{3}$ for a very short FDC (duration of one week) and a maximum at $100 \%$ for an OEC contract. A fourth result is that firms lower their norm when there are few unemployed and many vacancies. ITENS $S_{t}$ is the tension on the labor market and is given by $I T E N S_{t}=\frac{V_{t}}{U_{t}}$ with $V_{t}$ the vacancy rate and $U_{t}$ the unemployment rate at time $t$. The higher this tension, the more the firms have to lower their requirements if they want to find a candidate. $H$ is a logistic function with values between 0.8 and 1.2 and given by $H(x)=0.8+\frac{0.4}{1+20 \times e^{-3 x}}$.

This hiring norm is then decreased by a percentage $N_{4}$ in each period until the job is filled, but never drops below 0 . This decrease is justified by the limited duration of a job that lowers the expected profit as time to fill this job increases (Pissarides, 1976, p.50). A rising cost from holding the job vacant would have the same effect.

Hiring takes place in three steps:

1. Receiving applications - Firstly the firm receives applications from external applicants. and applications of internal candidates ${ }^{18}$.

2. Selection and potential hiring - A two-steps process takes place:

(a) First, the firm computes a score for each candidate (internal or external). The score for each candidate $i$ is computed as the expected profit $\Phi_{i, j, q, t}^{e s t i m a t e d}$ if the candidate is hired for the job. Then the best candidate (highest score) is selected.

(b) Thereafter, the firm checks if this candidate exceeds the hiring norm. If this is the case, the candidate is hired, otherwise, the job remains vacant.

3. Internal promotion - If the best candidate hired is an internal candidate of the company, it is a promotion. The employee acquires the occupation level of the job.

\subsection{Individual decisions (step 4-6 in Figure 1)}

The individuals take decisions in each period of the simulation. This decision process is modelled with a state machine, where one individual will be in one particular state: inactive, unemployed, employed and not searching for another job (denoted $E N S$ ), employed and seeking a

\footnotetext{
${ }^{18}$ Internal candidates are employees of the firm with a seniority greater than a certain threshold (SeniorityThreshold), and whose occupation is strictly one level lower to the occupation level of the job.
} 
new job (denoted OTJS, for On-The-Job Searchers), student or retired. The transitions between these states can be caused by individual choices (for example: to start studying, to quit a job...), by external events (firing, death...), or by a sequence of two decisions (applying for a job, and the firm hires the candidate).

\subsubsection{Utility functions}

Each individual uses a utility function, to decide whether she should stay in her current state or move to another one. The utility function has the generic form of a Cobb-Douglas function:

$$
U=(\text { Income }+ \text { Amenity }+ \text { Stability })^{1-\alpha}(\text { Free Time })^{\alpha}
$$

It is a weighted aggregation of two groups of factor, the income including the value of the characteristics of the job, and free time. The detailed factors are:

1. Income: weekly income of the household in euros, divided by the number of consumption units (an adult counts for 1, a child 0.5)

2. Amenity: non-monetary features perceived by the individual (social recognition, working environment, work hardness... $)^{19}$. It is converted into a percentage of salary and is expressed in euros.

3. Stability: criteria reflecting the preference of the individual for stability, i.e. for a job with the longest possible remaining contract duration. The maximum value is given for a permanent job (OEC). This stability is converted here into a percentage of salary and is expressed in euros;

4. Free time: free time per week available for the individual outside her working hours and her search time. Our definition is a broad one since it includes time devoted for instance to sleep, eating, washing, domestic duties, and notably caring for the children.

The parameter $\alpha \in[0,1]$ encodes the preference of the individual for free time or work. First, there is an effect of age, which increases the disutility of time spent at work. Hence $\alpha$ will evolve according to the following equation :

$$
\alpha=\alpha_{\text {base }} *\left(1+\alpha_{\text {old }} *(\text { age }-15)\right)
$$

With $\alpha_{\text {base }}$ drawn at the creation of the agent according to a normal distribution with mean $\alpha_{0}$ and standard deviation $\sigma_{a l p h a}$ (and with a minimum of zero).

Moreover. as in the ARTEMIS model (Ballot, 2002), $\alpha$ is different between men and women with children, because gender roles in the household has some impact ${ }^{20}$. We model this difference by multiplying the woman's alpha by a factor $F_{w}$ depending on the number of children in

\footnotetext{
${ }^{19}$ The amenity is a proxy for all the factors that make the work pleasant or painful. We consider the work time per period when we calculate this amenity to avoid a bias, and above all, the amenity is fully revealed to the employee only after hiring. This amenity discovery could cause some early quitting, as it is happening in reality. Thus, in terms of imperfect information, there is a symmetric process between amenity discovery for the employee and employee's productivity discovery for the employer. The main difference is that we assume the employee to be promptly informed of the amenity, while the productivity is measured only very gradually (the probationary period is too short to reveal the real productivity).

${ }^{20}$ In fact, and even if societies are constantly evolving on that issue. French women in 2011 have devoted more time than men to housework and the education of children. According to INSEE's enquiry on time use (2010), on average (including persons withot children), women devote $45 \mathrm{mn}$ daily to care for children, while men spend only $19 \mathrm{mn}$ on such an activity. Indeed, in 2011, the employment rate of French women working full-time and living in a couple with three children or more was $39.8 \%$ against $87 \%$ for men in the same situation (INSEE, 2011b)
} 
the household : $F_{w}=1+\alpha_{\text {child } 1} *(1+\# \text { children })^{\alpha_{\text {child } 2}}$. For women under 25 and having children, this alpha is further multiplied by a factor $\left(1+\alpha_{\text {youngWomen }}\right)$.

\subsubsection{Overview of the decision-making process}

The decision-making process of individuals is sequential. The transition from one state to another is done by comparing the utility level of the current state with the expected utility level in a new state. ${ }^{21}$ Each reachable state will be evaluated using the relevant values of income, amenity, stability and free time in the utility function, the difficulty to reach it, and the psychological cost of starting to search (ICHANG). The agent can then decide whether it is better for her to stay in his current state or to move to another one, as we see on Figure 2. In this case, the individual stops her decision process and changes state, as prescribed by Simon's satisficing heuristics (Simon, 1956).

Every month, an individual in the inactive or the employed state receives information about NPros new jobs p prospected. This list of known jobs is obtained by randomly drawing a list of jobs among all job vacancies of JobAds that match the current occupation of the individual. On the basis of these informations she receives on these jobs, she evaluates $U T N E W$, which represents the interest to start looking for another job .

Reservation utility calculation for the unemployed and On-The-Job-search states The reservation utility of the unemployed evolves according to the following equation :

$U T R E S_{i, t}=U T R E S_{i, t-1} \times\left(1-\operatorname{Param}_{U T R E S}\right)+\operatorname{Param}_{U T R E S} \times\left(U T U E M_{i, t}-U T U E M_{i, t-1}\right)$

If a worker becomes unemployed by quitting, or has a job but considers looking for another job, the initial reservation utility of the individual $U T R E S_{i, 0}$ is computed from the list of all the jobs known during the free search: If an employee becomes unemployed because she is fired, $U T R E S_{i, 0}$ is initialized at $U T E M P_{i, t}$, the utility of the job lost: the individual has no higher requirement. The reservation utility decreases at the rate of $1-\operatorname{Param} 3_{U T R E S}$ with the seniority in unemployment. Param $3_{U T R E S}$ is a calibrated parameter. $U T R E S_{i, t}$ depends also on the changes in her myopic utility $U T U E M_{i, t}$ with a sensitivity coefficient Param $4_{U T R E S}$, a calibrated parameter. This myopic utility reflects the income per unit in the period (unemployment benefit, $\mathrm{RSA}^{22}$...) and free time reduced by the time spent to search a job every week. This means that this myopic utility can rise (or fall) and $U T R E S_{i, t}$ accordingly. ${ }^{23}$

In the case of an On-the-Job-Search (OTJS) worker, her reservation utility is given by :

$U T R E S_{i, t}=U T R E S_{i, t-1} \times\left(1-\operatorname{Param}_{U T R E S}\right)$.

\footnotetext{
${ }^{21}$ However, for states perceives as temporary, such as unemployment, the individual takes into account in the utility of this state the expectation of a future job. See below.

${ }^{22}$ as for "Revenu de solidarité active". In France, this a minimum income for people without resources. In 2011, the RSA was $467 €$ per month for a single person aged 25 or more.

${ }^{23}$ We distinguish this myopic utility to be unemployed $U T U E M_{i, t}$ from the dynamic reservation utility $U T R E S_{i, t}$ according to search theory that takes into account the expectation to get a job with an expected salary. This dynamic reservation utility remains based on bounded rationality, since searchers do not anticipate the possible breach of the contract they look for, and the values of the many states beyond.
} 


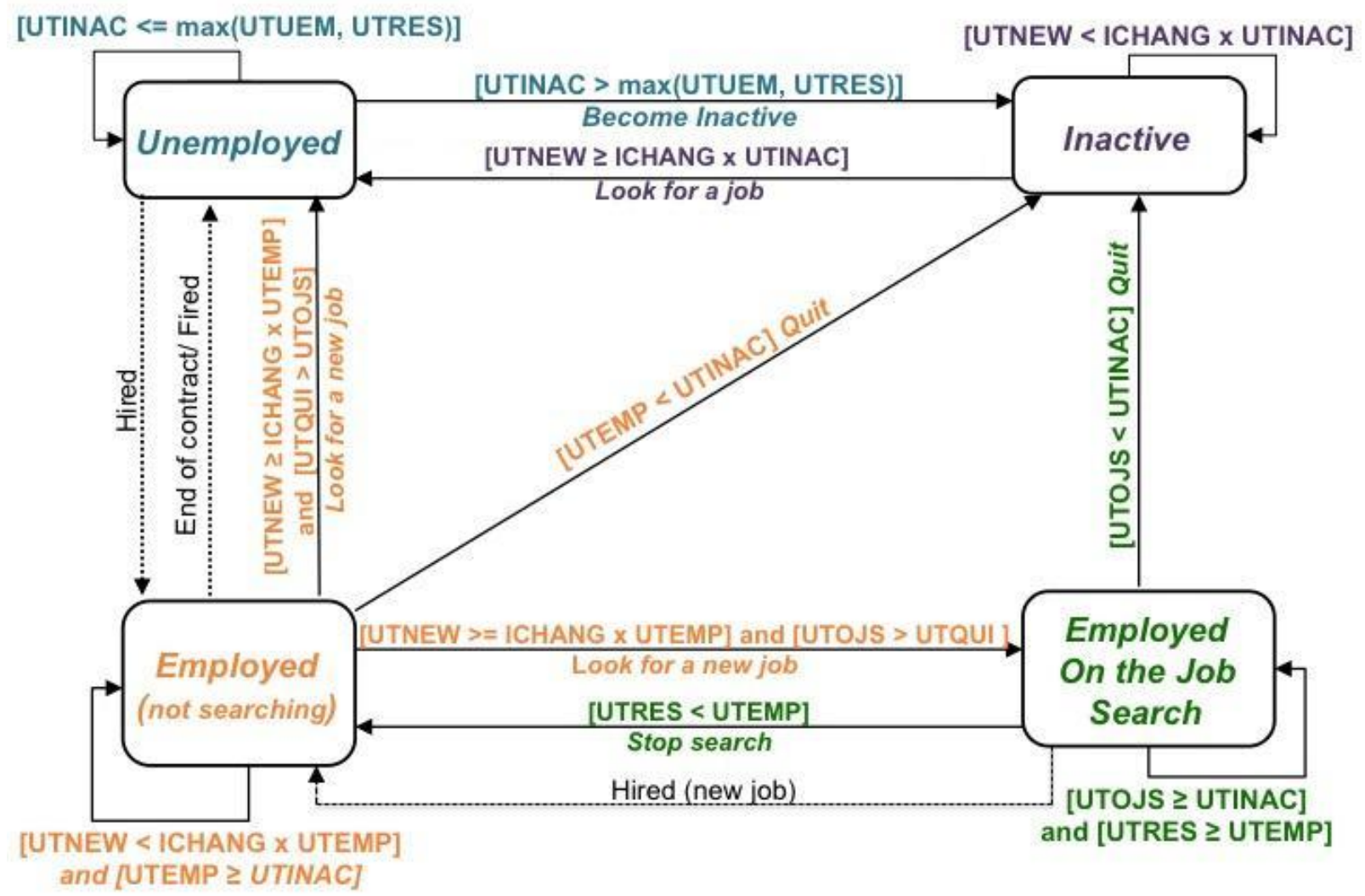

Figure 2: State diagram describing the main transitions of individuals and their decision-making process. Each utility is calculated according to the equation 16. Legend: UTINAC: utility to be inactive. UTNEW: utility of a new job, estimated through prospecting. UTUEM: utility to be unemployed. UTRES: utility of reservation. UOTJS: utility of the OTJS (On-the-Job-Search) state. UTEMP: utility to be employed. UTQUI: utility to quit. ICHANG psychological cost to start searching for a job (calibrated exogenous parameter). Dotted arrows represent decisions that do not fully depend on the agent (i.e. taken by the firm).

\subsubsection{Decision of student and public servant agent}

Given the variety of possible situations, we found difficult to model the behavior of students in this first version of WorkSim. We took a "black box" approach, simply aiming to reproduce the flow of students towards activity on the labor market in 2011.

Furthermore, the public servant agents (21.3\% of the agents) do not take decisions and are just present in order to reproduce demographic and employment statistics. When they retire, they are replaced according to a rate 1:1 (to be in a steady state) by young people who are finishing their studies and are randomly drawn in their cohort. 


\subsubsection{Job search process}

After describing the different decision mechanisms, let us now detail the overall job search process:

1. Each period in the model (one week in the reality), a job seeker receives from JobAds a list of NPros vacancies matching its occupation level or a level above. At time $t$, this number of vacancies NPros is determined according to a Poisson distribution with parameter $\lambda_{t}=$ $N \operatorname{Pros}_{A v g} \times \frac{I T E N S_{t}}{I T E N S_{r e f}}$.

(a) $N \operatorname{Pros}_{A v g}$ is the average number of vacancies received by the unemployed each week and set at the value of 3 .

(b) ITEN $S_{t}$ is the tension on the labor market at time t and ITENS $S_{\text {ref }}$ is the tension on the labor market for the reference year we study $\left(I T E N S_{r e f}=\frac{V_{r e f}}{U_{r e f}}=\frac{0.044}{0.092}=0.48\right.$ in 2011). The higher the vacancy rate and the lower the unemployment rate, the more the job seekers receive vacancies each period.

2. The individual applies each period for the first offer she receives with a utility at least as high as her reservation utility $U T R E S_{i, t}$.

3. At each step, if the individual looking for a job does not receive any job offer corresponding to her occupation level or if all of her applications are rejected, she lowers her reservation utility $U T R E S_{i, t}$.

\section{Model calibration}

\subsection{Scaling}

In order not to exceed our computation power, we limit the total number of agents to 10000 . To do so we first scale down the number of firms to reproduce the distribution of firms by size in France in 2011 (INSEE, 2011a). This gives a reduction factor of $1 / 4700$ and a total of 808 firms. From this firm distribution we derive the number of employees, 4411 in our case. Then, we add public servants in a proportion of $21.3 \%$ (INSEE Source (INSEE, 2013b)), and the numbers of "inactive", "unemployed", "retired" and "student" agents corresponding to 2011 statistics (INSEE, 2011d). We obtain a total of 8713 individual agents and it corresponds to the 40.79 million individuals in the age range 15-64 with a reduction factor of 4682 (which is well in line with the reduction factor for the firms). Finally, we have then a total of 9521 agents in the simulation.

\subsection{Minimization of a fitness function}

To calibrate the model parameters (37) we minimize a fitness function that is the weighted sum of the relative spreads between the outputs of our model and the real targets of the French labor market in 2011 (source INSEE/DARES). We have chosen 49 main targets grouped in 7 different categories:

- 7 targets on unemployment rate by age group and by occupation level (INSEE, 2011c)

- 6 targets on activity rate by age group and by gender (INSEE, 2011b) 
- 20 targets on wages by age group and by occupation levels, and annual wages distribution per decile on the global population (INSEE, 2013a)

- 9 targets on labor flows (DARES, Octobre 2012) (the global column values in Table 1 below)

- 9 targets on annual transition rate (Jauneau \& Nouel de Buzonniere, 2011) ${ }^{24}$.

- 3 targets on share of long term unemployment in unemployment by age group (INSEE, 2011d)

- 4 additional targets on part-time job proportion in employment (INSEE, 2011d), vacancy rate (Conseil d'Orientation pour l'Emploi (COE), 2013), the ratio of employed "looking for a new job” (OTJS) (INSEE, 2008) and the share of FDC in total employment (INSEE, 2011d).

\subsection{Calibration method}

This fitness function is minimized at a horizon of 200 periods (each period corresponds to one week). To minimize our fitness function, we choose the evolutionary algorithm CMA-ES (Hansen \& Ostermeier, 2001), which is one of the most powerful algorithms to solve this kind of problem (Auger \& Hansen, 2012).

CMA-ES means Covariance Matrix Adaptation Evolution Strategy. The principle of this evolutionary algorithm, inspired by biology, is to test step by step new generations of points in the parameters space. Each new generation of points is drawn stochastically according to the results obtained with the previous generation of points. The mean and the covariance matrix of the distribution of the new randomly drawn points is updated incrementally in order to move towards the best results obtained by previous generations.

Once the fitness function is minimized at the horizon of 200 periods in a steady state, we verify that a steady state is actually reached. This steady state is not devoid of a drift : however, on average, the simulated outputs for the targets have changed by less than $5 \%$ after 200 periods.

\subsection{Results of the calibration on the main targets}

We obtain the results shown in Appendix $\mathrm{C}$ for the main targets of our calibration in a steady state (the different rates are expressed in \%), the outputs are averaged over 200 simulations. The values of the calibrated parameters are shown in Appendix D. We obtain an average relative spread between all the outputs of our model and the real targets of $12.9 \%$. The average spread can be deemed satisfactory for such a large non-linear model.

\subsubsection{Comparison of simulated flows with DMMO survey}

The DMMO (Déclarations mensuelles des Mouvements de Main-d'Oeuvre) is the only French source that measures several types of gross flows, yet only a small part of all types of gross flows, and therefore does not provide full accounts of labor flows. Yet it is of interest to verify whether other types of flows, which were not in our fitness function, are accurate or not. Therefore, we compare the workforce flows by age group calculated by WorkSim with the same variables calculated by DARES and based on DMMO (DARES, Octobre 2012). These entry and exit rates are

\footnotetext{
${ }^{24}$ These targets could not be found for later than 2007. However. these transitions are not too volatile. even the partial information we have obtained for 2011 displays the effects of the crisis - see table 2.
} 
ratios between gross entry or exit numbers during the 2011 year over the number of employed persons at the beginning of the year (they are not probabilities to move from a state to another).

We note that most work flows calculated by WorkSim are close to DMMO, or at least the hierarchies of magnitudes by age groups are consistent. (cf. Table 1). Improvements require the introduction of more detailed institutions and behavior, and are left to future developments of the model.

\begin{tabular}{|l|c|c|c|c|c|c|c|c|}
\hline & \multicolumn{4}{|c|}{ WorkSim outputs } & \multicolumn{3}{c|}{ Source: Dares. DMMO/EMMO } \\
\hline & Global & $<30$ & 30 to 49 & $>50$ & Global & $<30$ & 30 à 49 & $>50$ \\
\hline \hline Entry rate & 49.1 & 88.0 & 37.8 & 37.0 & 51.0 & 115.0 & 36.6 & 23.7 \\
\hline Entry in FDC rate & 39.8 & 75.0 & 30.0 & 28.3 & 40.0 & 92.1 & 27.5 & 19.2 \\
\hline Entry in OEC rate & 9.3 & 13.1 & 7.7 & 8.7 & 11.1 & 23.0 & 9.1 & 4.6 \\
\hline Exit rate & 46.4 & 75.4 & 36.4 & 40.5 & 49.4 & 104.3 & 36.0 & 28.2 \\
\hline Exit for FDC end & 31.7 & 56.6 & 24.7 & 23.7 & 35.2 & 79.2 & 24.6 & 17.9 \\
\hline Quit rate & 5.9 & 11.9 & 4.8 & 2.9 & 6.5 & 13.9 & 5.4 & 2.2 \\
\hline end of probationary period rate & 3.1 & 3.8 & 2.6 & 3.2 & 2.0 & 4.9 & 1.4 & 0.6 \\
\hline dismissal for eco. reasons rate & 0.24 & 0.3 & 0.2 & 0.21 & 0.5 & 0.4 & 0.5 & 0.6 \\
\hline dismissal for other reasons rate & 4.1 & 2.7 & 4.0 & 5.0 & 3.2 & 4.3 & 3.1 & 2.5 \\
\hline
\end{tabular}

Table 1: Comparison of flow rates by age group WorkSim/Dares

\subsubsection{Comparison of simulated annual transition rates with the Employment Survey}

We now compare the annual transition rate of individuals calculated by the model with those obtained empirically from the Employment Survey 2007 (Jauneau \& Nouel de Buzonniere, 2011), last year for that we have found the annual transition matrix. For 2011 we found only 3 transition rates in (INSEE, 2014). The transitions are based on questionnaires by comparing individual states at a certain date in year $\mathrm{n}$ and the same date in year $\mathrm{n}+1$ (with a 12 months distance). A number in a state $\mathrm{X}$ in year $\mathrm{n}+1$ comes from state $\mathrm{Y}$ in year $\mathrm{n}$. The ratio of (number in $\mathrm{X}$ )/ (number in $\mathrm{Y}$ ) gives the annual transition rate There are two interests in doing this comparison. First most of the empirical flow studies use these data. Second the Employment Survey defines unemployment as we do, according to the ILO norms, implying that only workers without a job and actively searching are labelled as unemployed.

We only aim to obtain a rough fit since the transition rates have been affected by the crisis between 2007 and 2011. The transition rates between the employment and unemployment obtained with our model are quite similar to the 2007 rate obtained from the Employment Survey (cf. Table 2). The lower transition rate of unemployment to employment (36.26\%) fits well the 2011 Employment Survey figure (37.6\%) and the higher stability into unemployment (56.8\%) fits better the new INSEE figure (44\% in 2011). Finally the transition from employment to unemployment (2.79\%) fits better the the new INSEE figure (2.9\%). These evolutions in our simulated data and the real data fit the effect of the 2008 crisis. The transition rates between inactivity and unemployment are however not well matched, but as Jauneau et al. (Jauneau \& Nouel de Buzonniere, 2011) show, measuring the inactivity and the flows it entertains with unemployment is a difficult endeavor because of statistical biases in the data. 


\begin{tabular}{|c|c|c|}
\hline & Simulated by WorkSim transitions & Transitions from 2007 Employment Survey \\
\hline Unemployment into Employment & $36.26 \%$ & $42.1 \%(37.6 \%$ in 2011) \\
\hline Unemployment into Inactivity & $6.98 \%$ & $17.5 \%$ \\
\hline Unemployment into Unemployment & $56.8 \%$ & $40.4 \%(44.0 \%$ in 2011) \\
\hline Employment into Unemployment & $2.79 \%$ & $2.5 \%(2.9 \%$ in 2011) \\
\hline Employment into Inactivity & $3.16 \%$ & $3.3 \%$ \\
\hline Employment into Employment & $94.06 \%$ & $94.3 \%$ \\
\hline Inactivity into Employment & $3.83 \%$ & $9.7 \%$ \\
\hline Inactivity into Unemployment & $2.02 \%$ & $4.7 \%$ \\
\hline Inactivity into Inactivity & $94.15 \%$ & $85.6 \%$ \\
\hline
\end{tabular}

Table 2: Comparison of annual transition rates WorkSim / Employment Survey

\subsubsection{Transition rates and the underestimation of gross flows}

One very important methodological point must be made here. One can notice that these figures capture the transitions between two dates separated by a full year, but do not capture the intermediate transitions that have taken place during the year, unlike those calculated from DMMO rates. A state such as unemployment is transitory for part of the workers concerned since the majority of unemployment spells $(60 \%)$ last less than a year. Thus, the annual transitions rates considerably underestimate mobility. The following computations illustrate this statement. The DUE (Déclarations Uniques d'Embauche) is another source than DMMO for the hires (but only covers the hires), and give an exhaustive account of these. It should be however mentioned that the DUE are intentions to hire, and that it is acknowledged that they overestimate hires by 5 to $10 \%$. We have taken from (Berche \& Vong, 2012) a figure for 2011 of 20.6 Millions of hires in OEC and FDC, which can be dispatched between 3.4 Millions OEC and 17.2 Millions FDC, and among these 13.1 Millions FDC of less than one month. If we compute the number of hires of unemployed by applying the transition rate of $37.6 \%$ in the Employment Survey, to the unemployed in our simulation (2.2 Millions - see our figure 16), we obtain 826448 hires. The DUE also include hires from employment as many workers change jobs. If we compute quits from the DMMO, we find 1.3 Millions moves that we will assume to be rehired. The hires in DUE without these quits are 19.3 Millions. The annual transition rates in the Employment Survey are then $4 \%$ of the DUE. The immense majority of hires on short run contracts are not captured by the annual Employment Survey, and this shows that the underestimation of gross flows is huge.

The Employment Survey has been made continuous since 2003, and transitions over short periods could in principal be computed. However the persons are interviewed once a quarter so that transitions under a quarter cannot be computed (Deroyon et al., 2013). A questionnaire on the preceding month allows to compute monthly transitions, but there is a retrospective memory bias. Morevover, these data have not been published. (Dubois et al., 2011) have treated the transitions between unemployment and employment under the assumption of homogeneity of the workers, and they find that the monthly transition from unemployment to employment is around 11\% in 2010 (figure 1 in their paper), which yields a flow of 241,780 moves per month. The DUE yields a monthly figure of 1.6 Million hires in 2011 (as we mentioned overestimating hires by $5 \%$ to $10 \%$ ). The ratio of transitions to the gross flows rises from $4 \%$ to $15 \%$ only. Our model captures $56 \%$ of the hires in the DUE, an underestimation that we have to accept if we want the other flows to fit the DMMO, which underestimate considerably the FDC of less than 
one month. However we capture the dominance of short FDC well enough since we simulate that $63 \%$ of FDC spells last one week, and $21 \%$ more than one week and less than one month ${ }^{25}$. Another way to look at the underestimation problem is to look at the duration of FDC and unemployment spells. Barlet et al. (2014) measure a median spell for the FDC of 2 weeks in 2012. These statistics mean that most of FDC could not captured by any enquiry that has a step of one month or more, and hence the flows between FDC and unemployment (and the other way) lead to a huge underestimation of gross flows even if computing monthly transitions. Data on (completed) unemployment spells by duration are not available, but they would certainly confirm that many short spells are underestimated by transitions matrices. In our model, $27 \%$ of the spells of unemployment among those completed during the year last at most two weeks and $50 \%$ last at most one month ${ }^{26}$.

\subsubsection{Unemployment by age and occupation group}

The WorkSim model allows to compute detailed data on the characteristics of unemployment by age group and occupation level, shown in Table 3 below. First we note that the average duration of unemployment spells is much lower than the average unemployment seniority. This reflects a composition effect (the most employable of the unemployed individuals find a job quickly) and possibly a duration dependance effect (a decrease of the exit rate when unemployment seniority increases). The latter effect is however a controversial issue in the empirical studies (OECD, 2011), and since the evolution of the reservation utility with the unemployment seniority is an important factor of exit intensity in the model, we formalize three effects :

- the seniority of unemployment has a negative effect on the reservation utility, since the unemployed understands she cannot succeed to obtain the good jobs she has applied to, and this raises the hiring rate

- the decrease in the replacement rate when the unemployment redundancy is replaced by welfare reinforces this reservation utility decrease, and this has a positive effect on the hiring rate

- finally the decrease in the reservation utility may induce some unemployed to exit to inactivity

All these effects decrease unemployment. However, the seniority of unemployment induces a progressive loss of human capital after six month that decreases the hiring rate and increases unemployment. The net effect of these opposed factors is the existence of a very substantial proportion of long term unemployed. The long-term unemployment is well reproduced as a proportion of total unemployed persons. On average, in our model, $34.5 \%$ of the unemployed persons have been unemployed for more than 1 year and $26 \%$ for more than 2 years (which is not very far from the $40.5 \%$ and $19 \%$ rate respectively obtained with the Employment Survey (INSEE, 2011d).

\footnotetext{
${ }^{25}$ According to Berche, Hagneré \& Wong (Berche et al., 2011), in 2010, 46.2\% of total hires are for FDC one week or less, and $18 \%$ less than one month (statistics based on the DUE).

${ }^{26}$ Gradin et al (2015) show that $20 \%$ of unemployment spells in Spain last less than one month in 2007, a fact easy to explain by the weight of FDC in this country.
} 


\begin{tabular}{|l|c|c|c|c|}
\hline & Global & 1524 years & 2549 years & 5064 years \\
\hline \hline Share of long-term unemployed - more than 1 year & $34.5 \%(3.4 \%)^{*}$ & $26.3 \%(3.6 \%)$ & $38.5 \%(2.8 \%)$ & $34.8 \%(3.4 \%)$ \\
\hline Share of long-term unemployed - more than 2 years & $26.0 \%(2.1 \%)$ & $16.0 \%(2.2 \%)$ & $30.3 \%(3.1 \%)$ & $27.7 \%(3.7 \%)$ \\
\hline Average unemployement seniority (in month) & $13.9(0.90)$ & $10.4(0.69)$ & $15.4(0.97)$ & $14.4(1.21)$ \\
\hline Average duration of unemployment spells (in months) & $2.59(0.71)$ & $3.14(0.19)$ & $2.28(0.22)$ & $2.51(0.25)$ \\
\hline
\end{tabular}

*The Figures in brackets are the standard deviations on the results

Table 3: Characteristics of unemployment by age in WorkSim

\section{Simulation analyzes and results}

We first undertake a sensitivity analysis on some important parameters in order to explore the model outputs, showing that the results can be interpreted through economic mechanisms that make sense. We then use the model to offer a first characterization of the nature of the French labor market.

\subsection{Sensitivity Analysis}

In order to perform the sensitivity analyzes, we run a set of simulations by changing the value of a given parameter step by step, the others remaining at their calibrated values. For each consecutive point, we measure the outputs of the model after 200 periods (4 years in reality) and average these results over 200 simulations in order to eliminate the stochastic effects. The results enable us to uncover if a parameter has a significant, null, or overwhelming role on the main features of the labor market. We analyze the effects of changing two different types of parameters. First we look at some of those which play a potentially important role in the behavior of the agents, namely the preference for free time, the cost of change to a new state, the speed of the decline of the reservation utility with the seniority of unemployment, and the change in the level of uncertainty of the employer on a newly hired worker. Second we submit the model to two types of aggregate shocks, one on demand, and the other on the parameter which influences the share of the wages in the total value.

\subsubsection{Preference for free time}

The parameter $\alpha_{0}$ represents the basic mean preference for free time in the computation of the free time parameter $\alpha$ (c.f. section 3.7.1 above). The higher $\alpha_{0}$, the higher is the preference for free time compared to wages and non-monetary job characteristics. An increase in $\alpha_{0}$ leads to greater valuation of free time that leads to a substantial decrease in activity (cf. Figure 3).

For the unemployment rate, when $\alpha$ raises and is below 0.23 , some unemployed stop to search and then the unemployment rate decreases. When $\alpha$ becomes somewhat higher than the calibrated value, the number of unemployed remain constant while the number of active persons decreases, which leads to an increase of the unemployment rate. Therefore the unemployment rate has a U-Shape (non monotonic). 


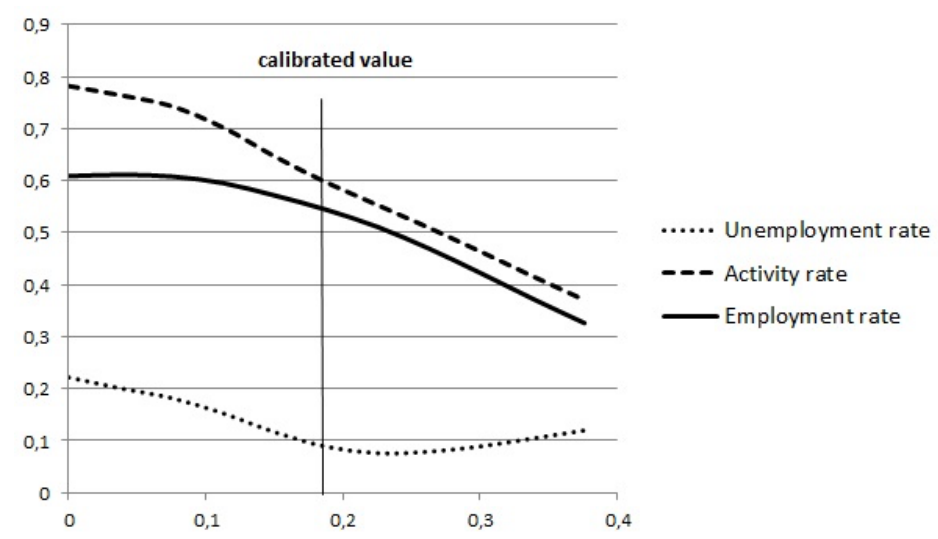

Figure 3: Sensitivity to the basic mean preference for free time $\alpha_{0}$

\subsubsection{Cost of change to a new state}

Mobility, and its inverse, stability in a state, is one of the crucial features to characterize a given aggregate labor market or the situation of some categories of labor when there is no homogeneity. The individuals will be less mobile when the cost of changing one's state rises. This cost is measured by the $I C H A N G$ parameter, which reflects psychological and economic transition costs (cf. section 3.7.2). When $I C H A N G$ is equal to 1 , there is no cost of entering the labor market and the activity rate is then higher as shown on Figure 4. When ICHANG decreases from its calibrated value 1.2 to become close to 1, we see on Figure 6 that the quit rate increases considerably, because more employed workers are looking for another job and quit their own job. This individual instability leads to a high turnover rate on the labor market and increases the unemployment rate (cf. Figure 5).

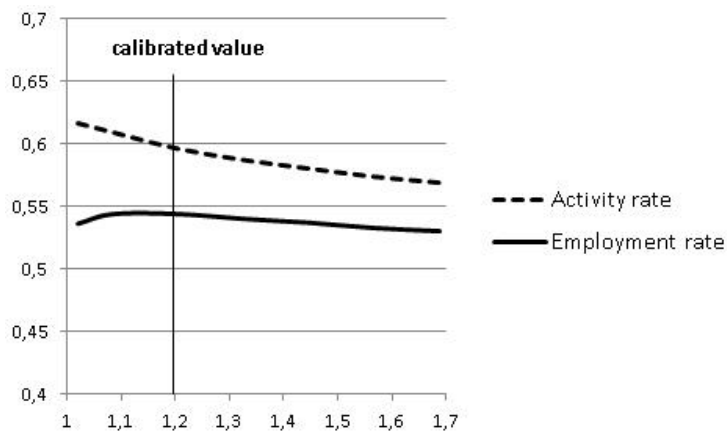

Figure 4: Sensitivity to the cost of change $I C H A N G$ 


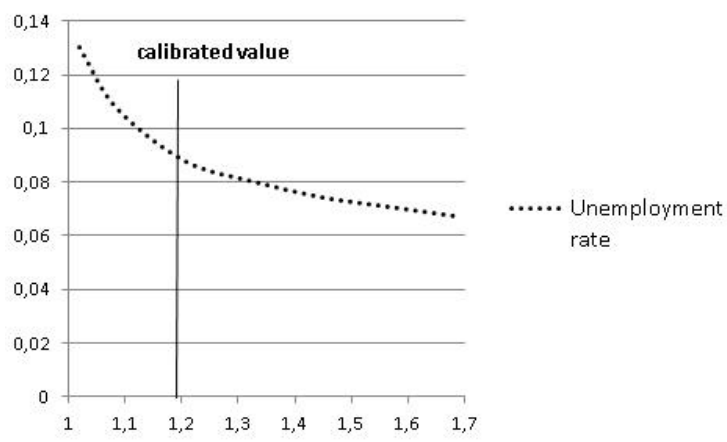

Figure 5: Sensitivity to the cost of change $I C H A N G$

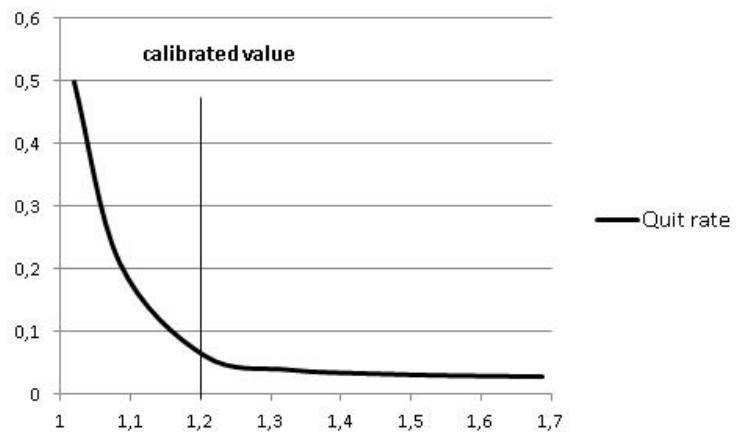

Figure 6: Sensitivity of the quit rate to cost of change $I C H A N G$

\subsubsection{Reservation utility decline with seniority in unemployment}

We now study the effect of the labor supply attitude of workers, and more precisely, in a search framework, one of the main parameters that determines it: the rate at which the workers decrease their reservation utility when their unemployment seniority increases. This rate is $\operatorname{Param} 3_{U T R E S}$ in our model, the reservation utility reduction parameter in equation 18.

We see in Figure 8 that the higher the reservation utility reduction parameter, the lower is the unemployment rate, because the unemployed revise faster their reservation utility in their job search process and then accept a high number of job offers. The same happens for the longterm unemployment rate (more than one year) and the effect is considerably more pronounced. This experiment highlights the existence of some search unemployment in the model,

Finally the faster reduction of the reservation utility induces some discouragement of unemployed persons, and the activity rate decreases (cf. Figure 7). 


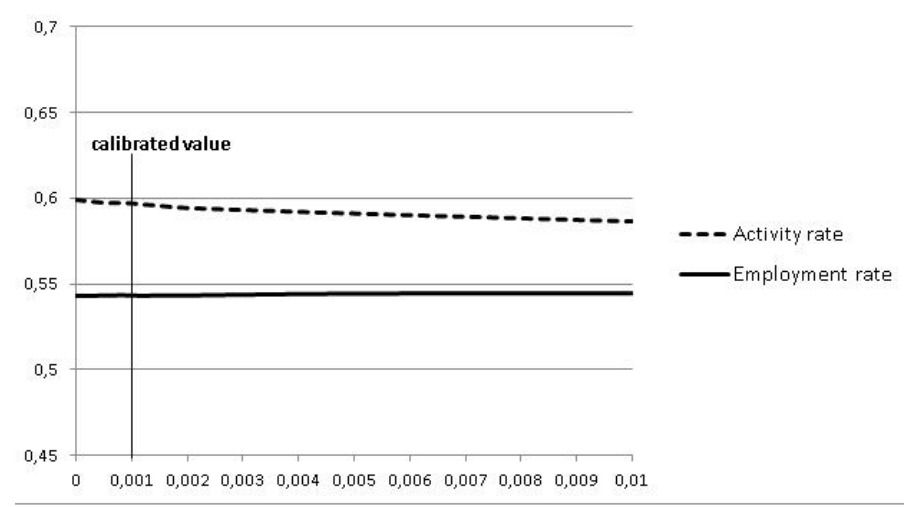

Figure 7: Sensitivity to the reservation utility parameter

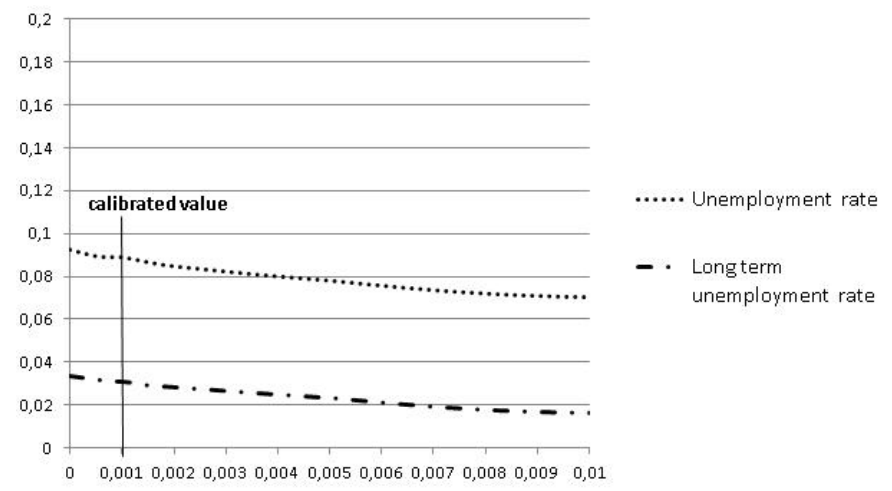

Figure 8: Sensitivity to reservation utility parameter

\subsubsection{Uncertainty on workers'productivity}

The parameter $\sigma_{0}$ represents the basic uncertainty of the firm when it evaluates the productions of its employees (equation 8).

This uncertainty reflects the organization of the production and its management. For instance, the tayloristic firm, in which the management decides the production process in minute detail, yields a low uncertainty while more modern organizations, that allow for more autonomy, lead to higher uncertainty. We see that an increase of uncertainty in the firm evaluation leads to higher entry and exit rates (cf. Figure 10). The firm makes more mistakes in its recruitment process and is more likely to fire on personal ground afterwards. We notice in Figure 9 that when uncertainty increases, the long-term unemployment decreases strongly, because the chance to get a job even with a weak core productivity is higher. This leads to a slight decrease of the global unemployment rate (from $10.3 \%$ to $9 \%$ ). 


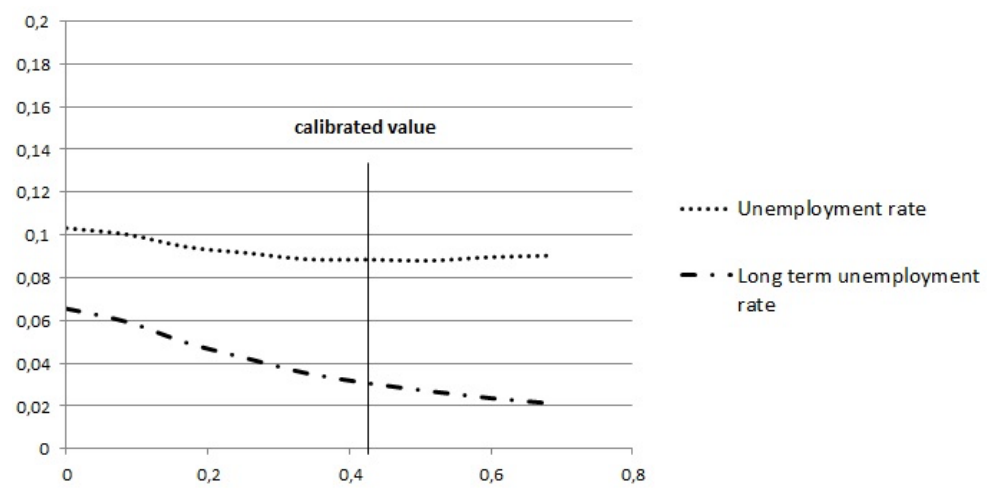

Figure 9: Sensitivity of the unemployment rate to uncertainty on production $\sigma_{0}$

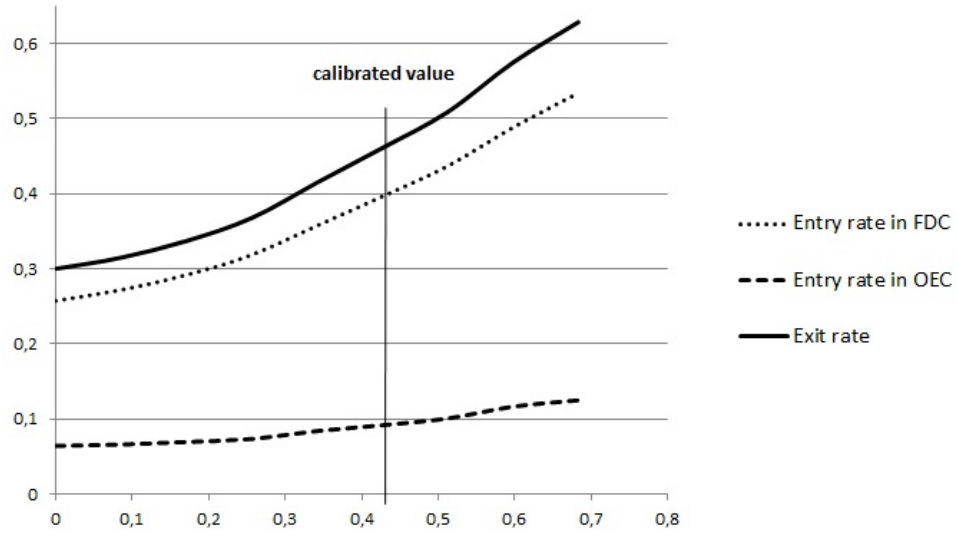

Figure 10: Sensitivity of the entry and exit rates to uncertainty on production $\sigma_{0}$

\subsection{Response to aggregate changes}

In this section, we aim to study the effects of some macroeconomic exogenous changes. Namely, we first analyze how the share of sales revenue between firms and workers impacts the main aggregates on the labor market, and then the market response to some aggregate demand shocks.

\subsubsection{Share of net wages in sales revenue}

The share of the sales revenue kept by the firm $\zeta$ determines the share of the workers $(1-\zeta)$, and more precisely the share of the net (real) wages, since the payroll charges are not included in the workers' wages (cf. equation 11). Because $\zeta$ is homogeneous over firms, changing $\zeta$ corresponds to a change in the balance of power between firms and workers. Results are shown in Figure 11. We observe a U-shape, and opposite effects on unemployment and employment rates, with a minimum unemployment rate of $9 \%$ for the calibrated value (cf. Figure $11 \mathrm{~b}$ ). If the share of firms is smaller and decreases $(\zeta<0.74)$, the unemployment increases because firms create fewer jobs. Jobs have indeed less chances to be profitable. Conversely, if the share of firms is higher and increases $(\zeta>0.74)$, the wages proposed to individuals decrease and the jobs become less and less attractive, which results in an increase in the unemployment rate, since participation 
does not decline much. Two factors explain this mild decline. First, when $\zeta$ approaches 1 (i.e. when the firm share is close to $100 \%$ ), wages will not drop to 0 since they must remain equal to the minimum legal net wage (1 072 euros per month in France in 2011), as displayed in Figure 12. Second the model does not offer to the individuals the possibility to become self-employed or undertake illegal activities to support themselves. Most of them then keep searching a job.

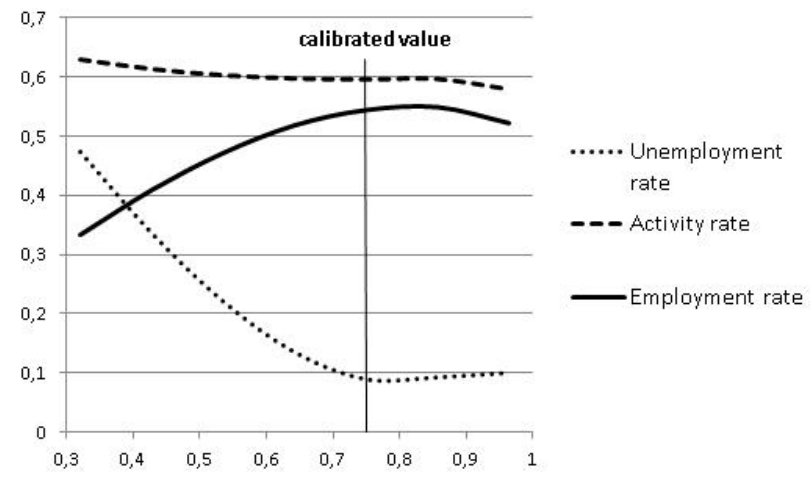

Figure 11: Sensitivity to the share of sales revenue $\zeta$

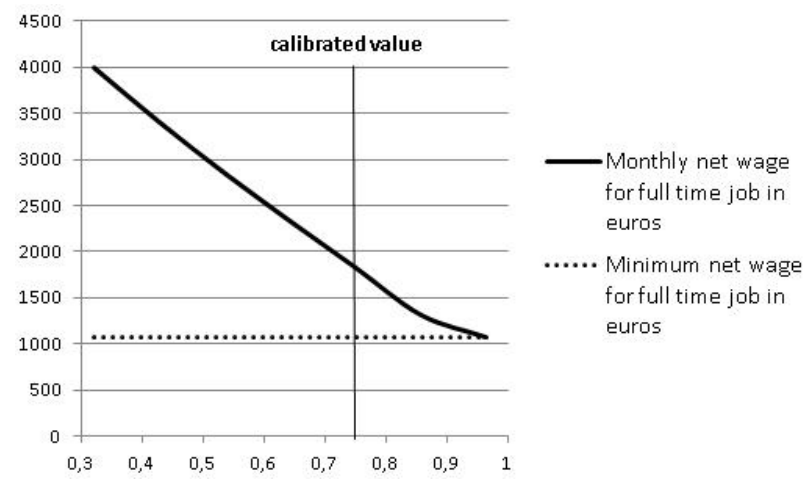

Figure 12: Sensitivity to the share of sales revenue $\zeta$

\subsubsection{Demand shocks}

Finally, we study a macroeconomic shock on global demand. To do so, we apply a multiplicative factor on the demand and observe the response of the model after 200 periods (4 years in the model).

If the demand shock is negative (aggregate demand factor falling under 1), the unemployment rate increases dramatically, which highlights an unemployment by lack of demand. When the demand factor is greater than 1 (demand increase), the unemployment rate decreases, but it does not decrease to zero, while the vacancy rate becomes very important. As found in real labor markets, there is a persistent unemployment caused by search on both sides, workers and employers. It can be characterized as a frictional unemployment, the level of which however depends also on the institutions of the labor market. This means that such factors (institutional or behavioral) as the firing costs, the level of unemployment benefits and welfare, the preference for free time and the rate of decrease of the reservation utility among others affect it (see Figure 13). 


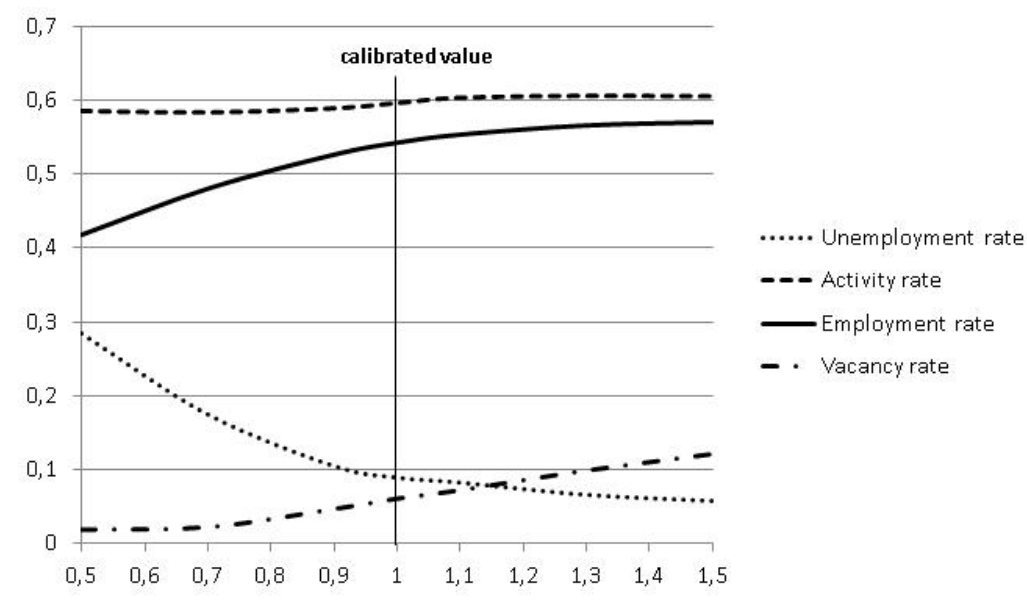

Figure 13: Simulated outputs after 200 periods as a function of aggregate demand factor

\subsection{Use of the model to characterize the French labor market: Flows and Segmenta- tion}

Finally, we study the weekly gross flows diagrams we derive directly from our simulations. Since the unit period is the week, no flow between two states is left unmeasured. Intra week flows are however theoretically possible and not taken into account, because the ILO and Employment Survey definition of unemployment makes it impossible to measure since it is enough to have worked one hour in the week to be considered as being employed during that whole week. The gross flows constitute a stock-flow consistent accounting system that no institution in France or elsewhere can build with the real data since the latter are not complete. The simulation model is thus a unique tool to obtain a complete and consistent description of the French flows, after calibration, and building this consistent accounting is the preliminary step to analysis. On practical grounds, as we have shown, it is less subject to the underestimation of flows that we find in the monthly or annual transition rates calculated from the Employment Survey. Thus we are ready to characterize our labor market and we will see how an important aggregate feature emerges: segmentation, and more precisely dualism. The model contains an institutional segmentation by the mere fact that at a point of time $90 \%$ of the workers are on an OEC job, while the other $10 \%$ are on a FDC job. The two types of jobs differ at least by the legal features of the contract and the unknown duration in the first case (but with the protection against a fast termination) and the fixed duration in the second case, duration that has a median value of 2 weeks in France. However a dualism implies more, and namely that some workers are stable in OEC while others move back and forth between unemployment and FDC, for a significant length of time or for most of their professional life.

We present the flow diagrams for all individuals and by age group (15-24, 25-49 and 50-64 years old), translated at the national level scale. Each type of flow is measured in two ways. First the numbers associated with the arrows indicate the number of agents in thousands who move from one state to another during the basic period, a week. The thickness of an arrow in the diagram shows the strength of a flow compared to the other flows. Second the percentage in brackets indicates the proportion of agents of a group who change state. This is computed as the ratio of the gross flow between two states on the number of the agents in the a state of origin. It can be labeled as the probability of transition from a state to another from a period to the next. These probabilities are very low because they are calculated on a weekly basis but exit probabil- 
ities from the same state can be compared and the relative probabilities can be interpreted in economic terms.

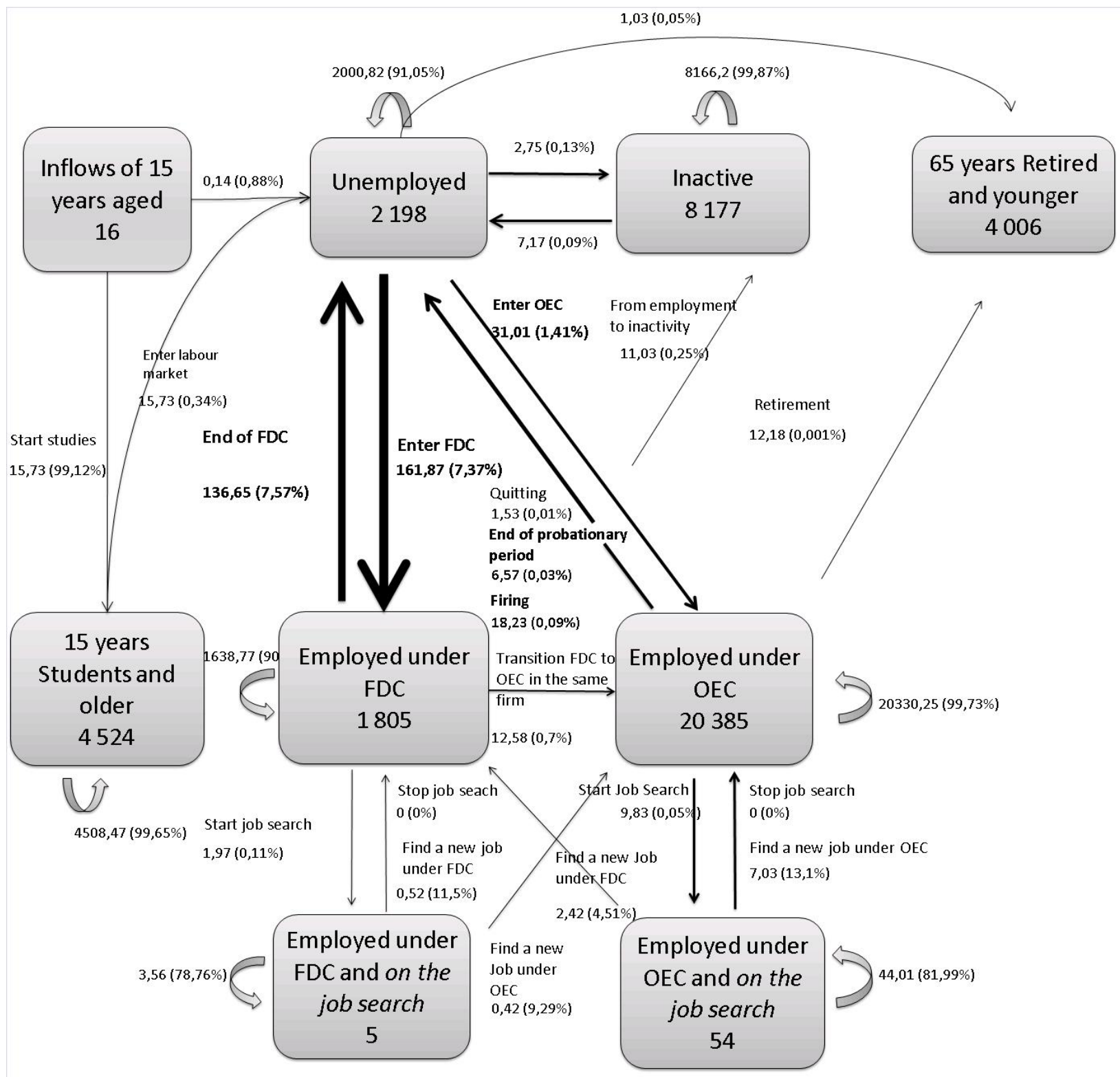

Figure 14: Gross Flows (all individuals; in thousands)

In the diagram for all individuals (Figure 14), the labor market is characterized by high rates of turnover between the states of "unemployed" and "Employed under FDC". The entry flow in FDC from unemployment is the largest of all flows with $162000^{27}$ persons per week and about five times greater than the flow of direct entry in OEC from unemployment, 31000 that is the third flow by order of importance ${ }^{28}$. Exit to unemployment from FDC, is also a major stream

\footnotetext{
${ }^{27}$ In this paragraph, we rounded the flow numbers given by WorkSim to ease the reading and comparisons.

${ }^{28}$ We could multiply the flow by 52 to obtain an annual flow. We do not since the numbers in the text would differ from those in the figure, which would be confusing. However, one can see that for the hires in FDC, it would yield a figure of 8.4 millions. This is half the number of FDC hires in the DUE. The simulated annual hires into OEC amount
} 
amounting to 137000 , the second in size. Exit from OEC to unemployment are much lower and constitutes the fourth flow with 26000 persons. The conversions of FDC into OEC represent only the fifth flow, 12600 with $8.4 \%$ of the exits from FDC (leaving aside the flows to inactivity and retirement), the other persons going into unemployment. It is an indicator of the stepping stone effect, since FDC offers potentially a chance for workers to obtain an integration in OEC in the same firm. However, this integration is a partial measure of the stepping stone effect as there is also a longer term effect, by which experience acquired in FDC may favor later integration into OEC in an other firm. In our simulation, we find that $22 \%$ of individuals in FDC are working in OEC one year later.

Therefore, a first and important observation is that FDC generate important flows towards unemployment and from unemployment to FDC, but at this stage we cannot say whether this mobility is concentrated or not on a rather small fraction of the agents, and consequently if there is segmentation, or not. There are two extreme stories to interpret the data. A first story is segmentation: some workers alternate precarious FDC, which are generally short as mentioned, and periods of unemployment. The other workers are employed in very stable OEC, even if some of these workers can lose their jobs because they are fired for personal or economic motives. The second story is integration with a delay: it tells that FDC is mainly a stepping stone to obtain an OEC later, but one that might require a significant number of spells in FDC to accumulate experience. In the latter case, the flow from unemployment to FDC should not be overwhelmingly large compared to the flow from unemployment to OEC, and the one from FDC to OEC. In the Figure 14, we see that the move from unemployment to FDC is 3.7 times larger than the sum of the moves from FDC to OEC and from unemployment to OEC. Thus, we infer that a segmentation between workers occurs in the sense that many workers on FDC are moving back and forth between FDC and unemployment (very few chose inactivity, only 2750), while other workers have long spells of employment on OEC (28 months in the model). Some are fired from OEC - the flow amounts to 12000 - and spend some time unemployed to find another OEC.

This is not the end of the story. If there is segmentation, the next issue is whether this segmentation is temporary for individuals or durable over the working life. The frontier between the two is not a precise figure, but an integration of young workers that would go beyond a period of 5 to 8 years after entry or say beyond being 30 years old, could be termed durable. Durable segmentation has very serious effects in terms of well-being on the cycle of life such as the difficulty to rent an accommodation and to obtain a loan to buy an accommodation, and brings the risk of exclusion. A temporary segmentation is an integration in an OEC after a difficult period in FDC and unmployment for those youths who have not obtained an OEC straightaway after their studies $^{29}$. In order to give some elements of answer on the durable character of the segmentation for a worker, we need to split the diagram by age groups, as depicted in the following Figures 15 and 16 below.

to 2.6 millions, to compare with the 3.4 millions in DUE. We underestimate because the model is calibrated on the DMMO that underestimate gross flows into short FDC, but the bias is slight compared to the bias in flows measured on a monthly transition matrix.

${ }^{29}$ This distinction would call for developments for which we do not have space in this paper, as well as an extensive explanation of the results. See Ballot (2002) (Ballot, 2002). p.72. who distinguishes static and dynamic segmentation. 


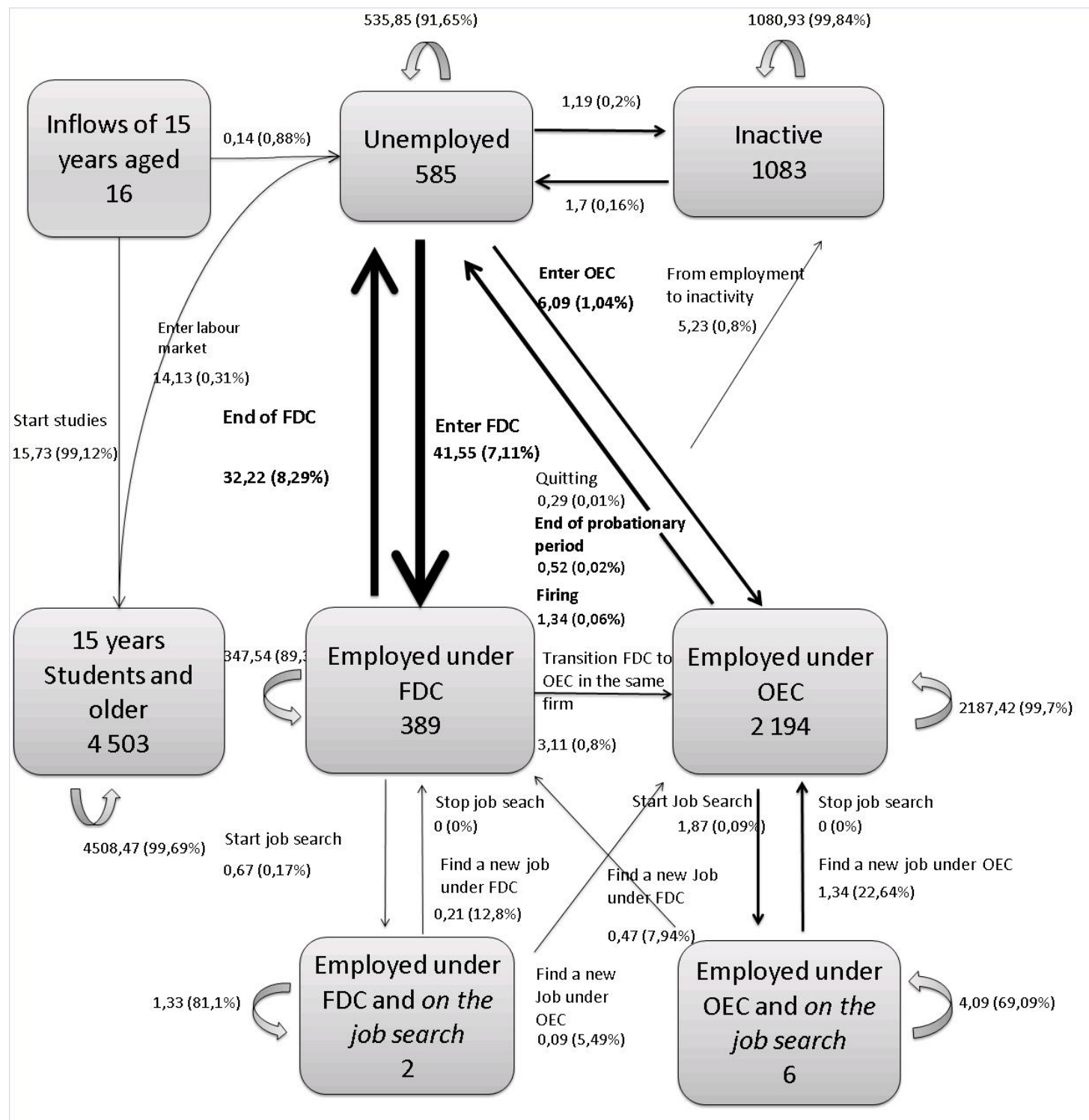

Figure 15: Gross flows 15-24 age group 


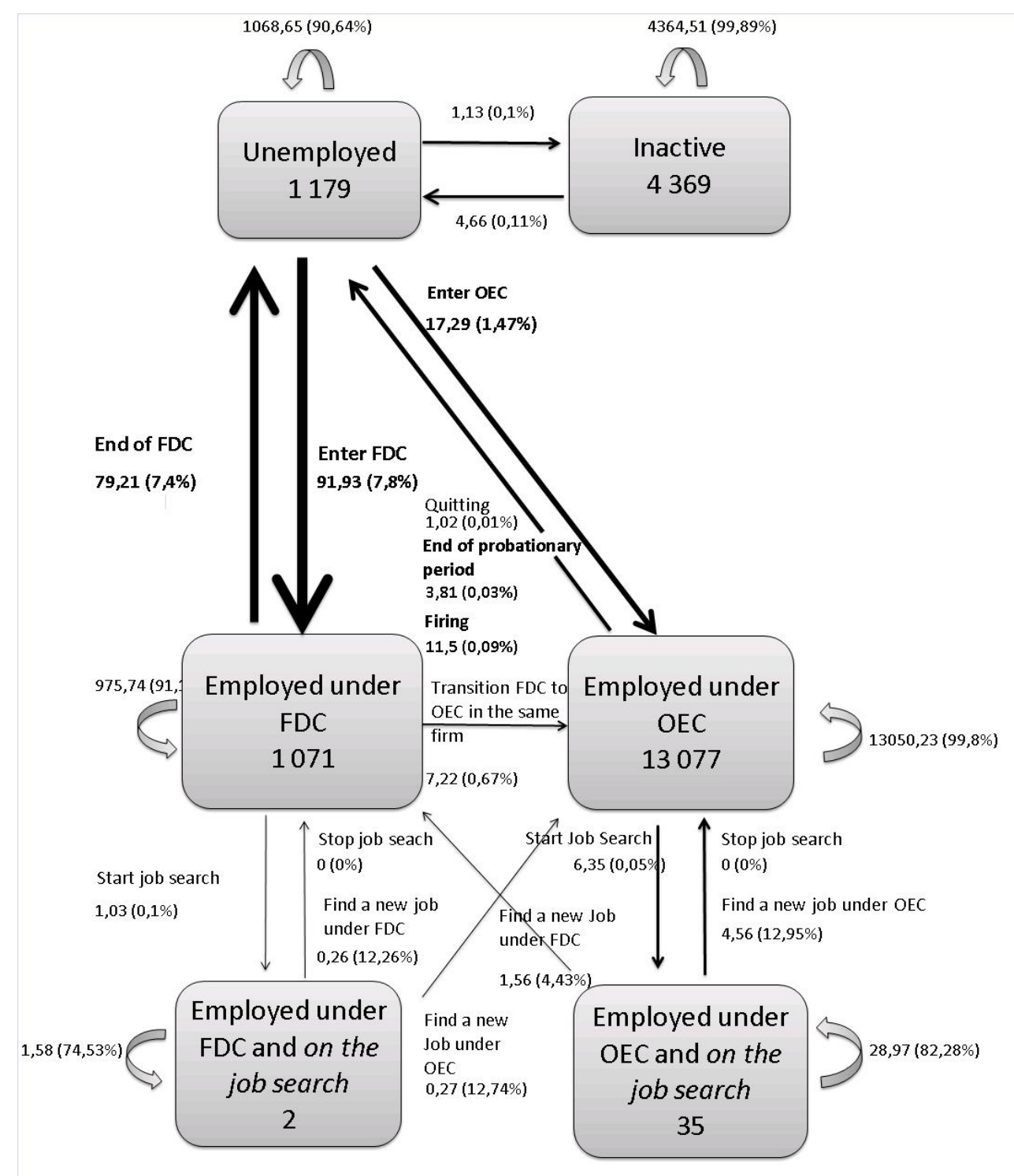

Figure 16: Gross flows 25-49 age group

The flow diagrams appear persistent between the 15-24 and the 25-49 age groups. The flows between unemployment and OEC remain fairly of the same order of magnitude in probabilities to move. The probability to move from unemployment into OEC is $1.47 \%$ per week for the $25-49$ age group, while it it is $1.04 \%$ for the $15-24$ age group, indicating that experience matters. The probability from OEC to unemployment is $0.13 \%$ for the $25-49$ age group while it is $0.09 \%$ for the 15-24 age group. It shows that the OEC are not life time jobs and that the 25-49 age group is not immune to contract termination. The conversions of FDC in OEC rate are not very high since they amount to $0.67 \%$ per week against $0.8 \%$ for the $15-24$ age group, nor is the recruitment in OEC, so that precariousness does not disappear. 


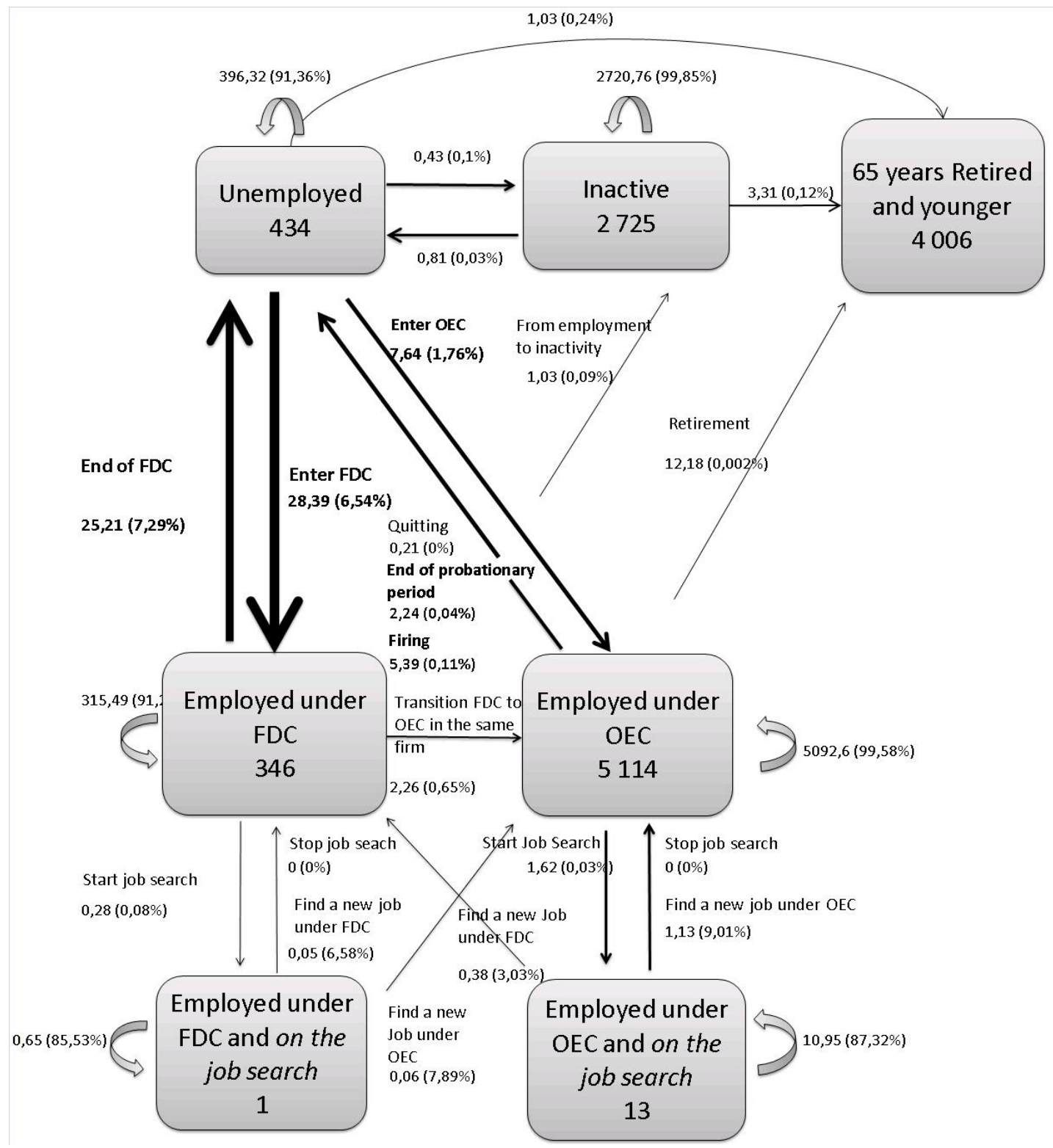

Figure 17: Gross flows 50-64 age group

The market for seniors (Figure 17) is similar to the market for the 25 - 49 age group except for the retirement flow. The flow rates between unemployment and FDC remain similar and substantial, as well as the hiring rate of unemployed into OEC (1.76\%), the exit rate from OEC to unemployment $(0,15 \%)$. The main new flow, which increases the total exit from OEC is the transition to retirement $(0.002 \%$ per week). Persistence of segmentation seems to occur.

A disaggregated analysis of the workforce by occupation levels will not be detailed here because of the lack of space. Its main conclusion is that the flows between FDC and unemployment are concentrated on blue collar workers and employees without disappearing in the other categories. The observations we made for the age groups point to a durable segmentation for a fraction of the young workers, while another fraction stabilizes into OEC. The Employee/blue collar occupation is specially concerned. Yet a precise assessment would require cohort analysis over the life cycle and a typology of the careers, as well as a comparison with the rare empirical 
studies that are available and cover only part of the life cycle. While the ABM tool is very fit for this analysis, which we have started to undertake, it will require a full paper to present it properly. The present paper analysis should be considered as a first step in our research program as far as this topic is concerned. 


\section{Conclusion}

In the version presented here, the WorkSim model provides a comprehensive theoretical framework of the labor market. Following ARTEMIS, WorkSim is the first to bring together a number of elements, which we consider jointly essential to characterize precisely the nature of a specific labor market, in order to have a tool for employment policies analysis:

1. the stock-flow accounting of individuals, based on gross flows, is complete and endogenous. It can be supplemented by a stock-flow accounting of jobs (and even jobs within the company) for further analysis. This is a preliminary step for a thorough analysis of a labor market.

2. the institutional environment is modeled and based on labor law, which sets constraints on the possible decisions.

3. the mobility is modeled through decision-making based on bounded rationality with learning. These decisions are made by the firms and the individuals, both heterogeneous. They are based on a search theory framework, which is rooted in the consideration of the cost of state change (search costs, mobility costs) in a decentralized market, and extended to a general theory of mobility. This theoretical framework provides an intellectual coherence to the many decisions modeled, and the many gross flows simulated. It also appears to have a higher analysis potential for the analysis of competition between categories of workers (for instance) both in the short run and over the life cycle than the matching model that assumes homogeneity. The results, for instance the emergence of segmentation, are however not the results of standard search theory and reflect the role of institutions that impinge at the micro level but have aggregate and possibly unexpected effects coming from the multiple interactions.

WorkSim is calibrated on a large number of targets of the French labor market in 2011, by implementing a powerful algorithm that has not already been used in economic models. It reproduces well enough these targets to conduct some economic analyzes. Moreover, it reproduces often well and sometimes very well the gross flows measured by different statistical sources and with different types of measures. It reproduces well gross flows of labor of the DMMO and many of the annual transitions calculated by the Employment Survey (Enquête Emploi). These statistics are widely used in analyzes and debates on the French labor market. The DMMO however gives an information on only some of the flows, which precludes a stock-flow accounting. WorkSim, by simultaneously fitting the gross flows of the DMMO and the annual transitions rates of the Employment Survey, uncovers the massive underestimation of mobility if these transitions are considered as a proxy of the gross flow rates. We also show that the monthly transitions measured by the Employment Survey (only for hires) diminish the underestimation of flows only in a marginal way.

This article presents a number of preliminary analyzes to characterize the French labor market, on the basis of complete individuals' stock-flow accounts, micro-decisions of heterogeneous agents, and institutions. We have studied several behavioral changes and aggregate shocks through sensitivity variants of some parameters. We show reactions of unemployment which we are able to explain by detailing the economic mechanisms at work in the model. The results may be sometimes unexpected ex-ante because of complex interactions. For example, the mean preference for free time and the share of sales revenue retained by the firms before the payment of salaries have a non-monotonic effect on unemployment. The latter has a slight U-shape. 
Our results also suggest a segmentation or dualism between workers, since some are stable in OEC because the number of dismissals is low, and some are rotating between FDC and unemployment. This dualism persists between the 15-24 years age group and the 25-49 years age group, and even the 50-65 group, so that the paper suggests it is permanent or at least durable, for a fraction of the workers. A fraction of young people do not seem to switch from FDC to OEC when they get older, contrary to the assumption of a gradual integration mechanism of young people involved by a temporary dualism.

Naturally, the key factor is the job creation, and the model reproduces well the massive effect of a sharp increase in aggregate demand on the reduction of unemployment. However, the primary objective of a model of the labor market is to study the effects of structural policies at a given aggregate demand level, although in fine some structural policies could influence demand and require to model some feedback mechanism.

\section{Future work}

Our research program is currently focused on a number of modules (extensions) to be integrated. The first aims to model (endogenously) the choice between FDC and OEC openings made by the firms. This is a complex issue that has not been solved to our sense in a formalized framework. This module will integrate the need for a required minimum level in human capital and training in some jobs and uncertainty on future demand that are fundamental elements in the labor market. Secondly, the choice of contracts will be extended to the temporary help contracts which have become empirically important and are presently included in the FDC, in order to bring into the scene the role of an intermediary in a decentralized market. Thirdly we might need a more detailed analysis of retirement to better analyze the seniors' market. A fourth module will focus on the analysis of careers. The characterization of the labor market requires an understanding of careers notably but not only in order to distinguish temporary segmentation and permanent segmentation. Existing empirical analyzes can serve as a benchmark, but are not able to reproduce full careers in a cohort, due to the lack of individual data over such a long period, and are biased by the changes in the economic environment during the lifetime. The multi-agent modeling seems to be an essential tool in this area, and this is a key reason for their construction, if one want to really understand the nature of the labor markets. 


\section{Appendix A: List of WorkSim agents characteristics}

\section{Individuals}

Specific attributes of individuals

- gender

- base alpha parameter (intensity of preference of the individual for free time)

- initial occupation level when enter the labor market

\section{Internal variables of individuals}

- age between 15 and 65, which evolves during the simulation

- current occupation level (which can change if the individual receive a promotion)

- the state on the labor market: employed, OTJS (person employed and looking for an other job), unemployed. inactive, student, retired

- the firm, the job, the contract and the salary if employed

- salary history during all the career

- matrimonial status

- list of information about states and incomes of the other members of his/her household (partner and children). The model evolves in closed population, then the others members of the household are agents in the model.

- current alpha parameter (intensity of preference of the individual for free time), evolving during the simulation

- human capitals : general human capital on labor market, occupational human capital and specific human capital in a job of a firm

\section{Private Firms}

\section{Specific attributes of private firms}

- base productivity and base salary of its jobs by occupation level

- amenity of its jobs by occupation level: non-monetary characteristics evaluated imperfectly by the employed (e.g. working conditions....)

- share retained by the firm on employee's productivity value

- lists of employees, jobs and contracts

- list of vacancies 


\section{Appendix B: Parameters of the institutional framework}

\begin{tabular}{|c|c|c|}
\hline Parameter & Description & Value for France in 2011 \\
\hline FDCbonus & $\begin{array}{l}\text { Percentage of the gross wage given to the } \\
\text { employee at the end of a FDC if not converted in } \\
\text { an OEC }\end{array}$ & $10 \%$ \\
\hline FiringCost & $\begin{array}{l}\text { Firing cost of an employee in OEC depending on } \\
\text { his/her salary and seniority }\end{array}$ & cf. paragraph below \\
\hline NoticePeriodOEC & Legal dismissal advance notice period for an OEC & $\begin{array}{l}1 \text { month if employees' seniority } \\
\text { is below } 2 \text { years. } 2 \text { months } \\
\text { otherwise. }\end{array}$ \\
\hline EmployerCharges & $\begin{array}{l}\text { Percentage of employer's social security } \\
\text { contributions on net wage }\end{array}$ & $54 \%$ \\
\hline EmployeeCharges & $\begin{array}{l}\text { Percentage of employee's social security } \\
\text { contributions on net wage }\end{array}$ & $28 \%$ \\
\hline ReductionCharges $_{>20}$ & $\begin{array}{l}\text { Reduction of employer's charges at the SMIC level } \\
\text { for firms with } 20 \text { employees or more }\end{array}$ & $26 \%$ of gross wage \\
\hline ReductionCharges $_{<20}$ & $\begin{array}{l}\text { Reduction of employer's charges at the SMIC level } \\
\text { for firms with less than } 20 \text { employees }\end{array}$ & $28.1 \%$ of gross wage \\
\hline$S M I C$ & Monthly net minimum wage for a full-time job & $1072 €$ \\
\hline$R S A$ & Minimum income for people without ressources & $\begin{array}{l}467 € \text { per month for a single } \\
\text { person aged } 25 \text { or more }\end{array}$ \\
\hline$A L C H O$ & Unemployment benefits & $\begin{array}{l}\text { See (Service-Public.fr, 2011) for } \\
\text { the calculation }\end{array}$ \\
\hline ProbationaryPeriodFDC & Probationary period of a FDC & $\begin{array}{l}\text { One day per working week with } \\
\text { a limit of } 2 \text { weeks in the } \\
\text { expected duration of the } \\
\text { contract is below } 6 \text { months. } 1 \\
\text { month if the expected duration } \\
\text { of the contract is over } 6 \\
\text { months. }\end{array}$ \\
\hline ProbationaryPeriodOEC & Probationary period of a OEC & $\begin{array}{l}2 \text { months for blue collars. } 3 \\
\text { months for middle level } \\
\text { positions. } 4 \text { months for } \\
\text { executives. }\end{array}$ \\
\hline WorktimePerPeriod & Legal work time per week for a full time job & 35 hours \\
\hline AgeRetirement & Minimum retirement age for a full-rate pension & 65 years \\
\hline
\end{tabular}

\section{Firing costs in France in 2011}

In 2011, according to the article R. 1234-2 of the Labor Code in France in 2011, the severance pay for an employee dismissed is one fifth of one month's salary per year of seniority. For an employee with at least ten years of seniority, this severance pay is one fifth of one month's salary plus two fifteenth of one month's salary per year of seniority over ten years (According to the Labor laws L.1234-9, R.1234-2 and R.1234-4). The reference salary used to calculate the severance pay is the maximum between the average of the gross wages in the last 12 months and the average of the gross wages in the last 3 monts. 


\section{Appendix C: Calibration Results}

\begin{tabular}{|c|c|c|c|c|c|c|c|}
\cline { 2 - 7 } \multicolumn{1}{c|}{} & All & $15-24$ & $25-49$ & $50-64$ & Executives & Middle Level jobs & Employee/Workers \\
\hline WorkSim Outputs & $9.0(0.7)^{*}$ & $18.4(2.1)^{*}$ & $7.7(0.6)^{*}$ & $7.3(0.7)^{*}$ & $3.7(0.6)^{*}$ & $5.2(0.7)^{*}$ & $13.6(1.4)^{*}$ \\
\hline INSEE Source & 9.2 & 22 & 8.4 & 6.3 & 3.8 & 5.0 & 11.4 \\
\hline
\end{tabular}

*The Figures in brackets are the standard deviations on the results

Table 4: Targets on unemployment rate by age group and by occupational category

\begin{tabular}{|c|c|c|c|c|c|c|}
\cline { 2 - 7 } \multicolumn{1}{c|}{} & \multicolumn{3}{c|}{ Men } & \multicolumn{3}{c|}{ Women } \\
\cline { 2 - 7 } \multicolumn{1}{c|}{} & $15-24$ & $25-49$ & $50-64$ & $15-24$ & $25-49$ & $50-64$ \\
\hline WorkSim Outputs & 47.3 & 96.8 & 58.3 & 25.1 & 60.1 & 36.6 \\
\hline INSEE Source & 41.6 & 94.4 & 62.2 & $34 . .9$ & $83 . .9$ & $55 . .2$ \\
\hline
\end{tabular}

Table 5: Targets on activity rates by age group and gender

\begin{tabular}{|c|c|c|c|c|c|}
\cline { 2 - 6 } \multicolumn{1}{c|}{} & \multicolumn{5}{c|}{ Executives } \\
\cline { 2 - 6 } \multicolumn{1}{c|}{} & $<30$ & $30-39$ & $40-49$ & $50-59$ & $i 60$ \\
\hline WorkSim Outputs & 2096 & 2757 & 3222 & 3559 & 3837 \\
\hline INSEE Source & 2200 & 3192 & 4026 & 4295 & 5659 \\
\hline & \multicolumn{5}{|c|}{ Middle level jobs } \\
\hline WorkSim Outputs & 1289 & 1647 & 1954 & 2158 & 2342 \\
\hline INSEE Source & 1532 & 1791 & 1983 & 2091 & 2273 \\
\hline & \multicolumn{5}{|c|}{ Employee/Workers } \\
\hline WorkSim Outputs & 1072 & 1072 & 1073 & 1076 & 1084 \\
\hline INSEE Source & 1173 & 1313 & 1378 & 1447 & 1463 \\
\hline
\end{tabular}

Table 6: Salaries by age group and by occupational category

\begin{tabular}{|c|c|c|c|c|c|}
\hline & ler Decile & 1st Quartile & Median & 3rd Quartile & 9th Decile \\
\hline \hline WorkSim Outputs & 13936 & 13936 & 18228 & 30880 & 42164 \\
\hline INSEE Source & 14040 & 15660 & 20110 & 27350 & 39810 \\
\hline
\end{tabular}

Table 7: Annual net salaries distribution

\begin{tabular}{|c|c|c|c|c|c|c|c|}
\hline & \multicolumn{4}{|c|}{ Employment entry } & & & \\
\hline & Entry rate & Entry in FDC & En & try in OEC & & & \\
\hline WorkSim Outputs & 49.1 & 39.8 & & 9.3 & & & \\
\hline \multirow[t]{3}{*}{ DMMO Source } & 51.0 & 40.0 & & 11.1 & & & \\
\hline & \multicolumn{7}{|c|}{ Employment exits } \\
\hline & Exit rate & End of FDC & Quit & End of pro & ationary period & dismissal for eco. reasons & dismissal for othe \\
\hline WorkSim Outputs & 46.4 & 31.7 & 5.9 & & 3.1 & 0.24 & 4.1 \\
\hline DMMO Source & 49.4 & 35.2 & 6.5 & & 2.0 & 0.5 & 3.2 \\
\hline
\end{tabular}

Table 8: Workforce turnover 


\begin{tabular}{|c|c|c|c|}
\hline & $15-24$ & $25-49$ & $50-64$ \\
\hline \hline WorkSim Outputs & 25.8 & 38.1 & 34.6 \\
\hline INSEE Source & 28.4 & 41.9 & 57.8 \\
\hline
\end{tabular}

Table 9: Long term unemployment (more than 1 year) share in unemployment

\begin{tabular}{|c|c|c|c|c|}
\hline & Half-time job share in employment & Vacancy rate & OTJS rate & Share of FDC in employment \\
\hline \hline WorkSim Outputs & 16.3 & 5.8 & 0.3 & 8.1 \\
\hline INSEE Source/COE & 17.9 & 4.4 & 4.3 & 10.0 \\
\hline
\end{tabular}

Table 10: Additional targets 


\section{Appendix D: Calibrated exogenous parameters of the model}

\begin{tabular}{|c|c|c|}
\hline Parameter & Description & Calibrated value \\
\hline$\alpha_{0}$ & Average base factor for individual preference for free time & 0.188 \\
\hline$\alpha_{o l d}$ & $\begin{array}{l}\text { Increment of the factor for individual preference } \\
\text { for free time every year for an individual }\end{array}$ & 0.038 \\
\hline$\alpha_{\text {child } 1}$ & $\begin{array}{l}\text { First sensitivity parameter to the preference for free time of women } \\
\text { depending on the number of children in her household }\end{array}$ & 0.47 \\
\hline$\alpha_{\text {child } 2}$ & $\begin{array}{l}\text { Second sensitivity parameter to the preference for free time of women } \\
\text { depending on the number of children in her household }\end{array}$ & 1.29 \\
\hline$\alpha_{\text {youngWomen }}$ & $\begin{array}{l}\text { Specific sensitivity parameter to the preference for free time for young } \\
\text { women under } 25 \text { having children }\end{array}$ & 2.7 \\
\hline$I C H A N G$ & Psychological cost of starting to search for a job & 1.21 \\
\hline ProfitThreshold & Profit threshold under which the firm initiates a redundancy plan & $-4.5 \%$ \\
\hline$\sigma_{D}$ & Demand volatility of each firm & 0.0139 \\
\hline $\operatorname{PrLoss} X P$ & $\begin{array}{l}\text { Percentage of general experience loss each period after } 6 \text { month out of } \\
\text { employment }\end{array}$ & $0.018 \%$ \\
\hline UtilityContract & Base parameter for calculation of preference for contract stability & 7.3 \\
\hline sensiStabAge & Sensitivity factor to age in the preference for contract stability & 0.0002 \\
\hline$N_{1}$ & Parameter in hiring norm calculation & 0.50 \\
\hline$N_{3}$ & Parameter in hiring norm calculation & 0.049 \\
\hline$N_{4}$ & Parameter in hiring norm calculation & 0.0099 \\
\hline ParamUTRES $S_{1}$ & Parameter in reservation utility calculation & 1.69 \\
\hline ParamUTRE $S_{3}$ & Parameter in reservation utility calculation & 0.001 \\
\hline$\zeta$ & Share of sales revenue kept by the firm & 0.749 \\
\hline$P$ & Price of the good in the economy & 0.79 \\
\hline$\Psi_{\text {Executive }}$ & Mean share of the firm demand allocated to executive positions & 0.48 \\
\hline$\Psi_{\text {MiddleLevel }}$ & Mean share of the firm demand allocated to middle level positions & 0.33 \\
\hline$\beta_{\text {Excecutive }}$ & Increase factor of human capital with experience for executive jobs & 0.001 \\
\hline$\beta_{\text {MiddleLevel }}$ & Increase factor of human capital with experience for middle level jobs & 0.001 \\
\hline$\beta_{E O}$ & $\begin{array}{l}\text { Increase factor of human capital with experience for employee/worker } \\
\text { jobs }\end{array}$ & 0.0005 \\
\hline$\sigma_{C P r o d}$ & Standard deviation of the distribution of individual productivity core & 0.38 \\
\hline$\sigma_{0}$ & Initial standard deviation of employee productivity estimation by firms & 0.43 \\
\hline probaF $D C_{\text {Executive }}$ & Probability to draw a FDC contract when creating job for executives & 0.032 \\
\hline probaFDC $C_{\text {MiddleLevel }}$ & $\begin{array}{l}\text { Probability to draw a FDC contract when creating job for middle level } \\
\text { jobs }\end{array}$ & 0.585 \\
\hline probaFDC $C_{E O}$ & $\begin{array}{l}\text { Probability to draw a FDC contract when creating job for } \\
\text { employee/worker jobs }\end{array}$ & 0.97 \\
\hline$Q_{\text {Executive }}^{\text {base }}$ & Average base productivity of executive jobs & 2301 \\
\hline$Q_{\text {MiddleLevel }}^{\text {base }}$ & Average base productivity of middle level jobs & 1393 \\
\hline$Q_{\text {Employee/Workers }}^{\text {base }}$ & Average base productivity of employee/worker jobs & 671 \\
\hline EmployThreshold & $\begin{array}{l}\text { Employability threshold above which the individuals find themselves } \\
\text { employable }\end{array}$ & 220 \\
\hline ProbaFDC $C_{1 \text { week }}$ & Probability to draw duration of 1 week when creating a FDC contract & 0.59 \\
\hline ProbaFDC 1 month & Probability to draw duration of 1 month when creating a FDC contract & 0.18 \\
\hline ProbaFDC $C_{2 \text { months }}$ & Probability to draw duration of 2 months when creating a FDC contract & 0.091 \\
\hline ProbaFDC 6 months & Probability to draw duration of 6 months when creating a FDC contract & 0.016 \\
\hline ProbaFDC 12 months & $\begin{array}{l}\text { Probability to draw duration of } 12 \text { maths when creating a FDC } \\
\text { contract }\end{array}$ & 0.12 \\
\hline
\end{tabular}




\section{References}

Acemoglu, D. \& Pischke, J.-S. The structure of wages and investment in general training. Journal of Political Economy, 107, 1999.

Adams, J.S. Towards an understanding of inequity. Journal of abnormal and social psychology, 67(5), 1963.

Arrow, K. J. The economic implications of learning by doing. The review of economic studies, pages 155-173, 1962.

Auger, A. \& Hansen, N. Addressing numerical black-box optimization : CMAE-ES. LION 6, January 16-20, Paris, France, 2012.

Ballot, G. Marché du travail et dynamique de la répartition des revenus salariaux. Thèse pour le doctorat d'Etat d'Economie, Université Paris X-Nanterre, 1981.

Ballot, G. Concurrence entre catégories de main-d'Oeuvre et fonctionnement du marché du travail : l'expérience du modèle ARTEMIS. Ministère d'Etat chargé du Plan et de l'Aménagement du Territoire et Ministère du Travail, de l'Emploi et de la Formation professionnelle, Structures du marché de travail et politiques, Paris : Syros, page 224-240, 1988.

Ballot, G. Modeling the labor market as an evolving institution: model artemis. Journal of Economic Behavior and Organization, 49(1), p. 51-77, 2002.

Ballot, G. \& Taymaz, E. The dynamics of firms in a micro-to-macro model: The role of training, learning and innovation. Journal of Evolutionary Economics, 7(4), p. 435-457, 1997.

Ballot, G. \& Taymaz, E. Competition, training, heterogeneity persistence, and aggregate growth in a multi-agent evolutionary model. Ballot, G. and Weisbuch, G. (eds.), Applications of Simulation to Social Sciences, HERMES Science, Oxford, 2000.

Barlet, M., Blanchet, D., \& Le Barbanchon, T. Microsimulation et modèles d'agents; une approche alternative pour l'évaluation des politiques d'emploi. Economie et Statistique, pages 429-430, 51-76, 2009.

Barlet, M., Minni , C.and Ettouati, S., Finot, J., \& Paraire, X. Entre 2000 et 2012, forte hausse des embauches en contrats temporaires, mais stabilisation de la part des cdi dans l'emploi. DARES Analyses 56, DARES, July 2014.

Becker, G. S. Investment in human capital: effects on earnings. In Human Capital: A Theoretical and Empirical Analysis, with Special Reference to Education, 2nd ed. NBER, 1975.

Beffy, M., Buchinsky, M., Fougère, D., Kamionka, T., \& F., Kramarz. The returns to seniority in france (and why they are lower than in the US?). IZA DP, 1935, p. 155-173, 2006.

Berche, K., Hagneré, C., \& Vong, M. Les déclarations d'embauche entre 2000 et 2010 : une évolution marquée par la progression des CDD de moins d'un mois. Acoss Stat, (143), Décembre 2011.

Berche, K. \& Vong, M. La baisse des embauches de plus d'un mois se confirme au premier trimestre 2012. ACCOSTAT, (149), 2012. 
Bergmann, B. A microsimulation of the macroeconomy with explicitely represented money flows. Annals of Economic and Social Measurement, 3, p. 475-489, 2002.

Blanchflower, D. G. \& Oswald, A. J. The wage curve. The MIT Press, 1994.

Conseil d'Orientation pour l'Emploi (COE). Emplois durablement vacants et difficultés de recrutement. Rapport technique, 2013.

DARES. Les mouvements de main-d'oeuvre en 2011. DARES Analyses, (71), Octobre 2012.

Deroyon, T., Montaut, A., \& Pionnier, P.-A. Utilisation rétrospective de l'enquête emploi à une fréquence mensuelle : apport d'une modélisation espace-état. Document de travail, g2013/01f1301, INSEE, 2013.

Dubois, Y., Hairault, J.-O., Le Barbanchon, T., Sopraseuth, T., et al. Flux de travailleurs au cours du cycle conjoncturel. 2011.

Eliasson, G. A micro-to-macro model of the swedish economy. IUI, Stockholm, 1977.

Gibbons, R., Katz, L. F, Lemieux, T., \& Parent, D. Comparative advantage, learning, and sectoral wage determination. Journal of Labor Economics, 23(4), p. 681-724, 2005.

Gradín, C., Cantó, O., \& del Río, C. Unemployment and spell duration during the great recession in the EU. International Journal of Manpower, 36(2), p. 216-235, 2015.

Hansen, N. \& Ostermeier, A. Completely derandomized self-adaptation in evolution strategies. Evolutionary computation, 9(2), p. 159-195, 2001.

INSEE. Population active à la recherche d'un autre emploi (PARAE). (87), octobre 2008.

INSEE. Entreprises selon le nombre de salariés et l'activité en 2011. 2011a.

INSEE. Taux d'activité selon le sexe et la configuration familiale en 2011. 2011b.

INSEE. Taux de chômage par âge en 2011. 2011c.

INSEE. Une photographie du marché du travail en 2011. 2011d.

INSEE. Fiches thématiques - Synthèse des actifs occupés - Emploi et salaires - Insee Références - Édition 2013. 2013a.

INSEE. L'emploi dans la fonction publique en 2011. (1460), 2013b.

INSEE. Table insee natnon03324. Rapport technique, 2014.

Jauneau, Y. \& Nouel de Buzonniere, C. Transitions annuelles au sens du BIT sur le marché du travail. INSEE, 2011.

Jovanovic, B. Job matching and the theory of turnover. The Journal of Political Economy, 87(5, part 1), p. 972-990, October 1979.

Kambourov, G. \& Manovskii, I. Occupational specificity of human capital*. International Economic Review, 50(1), p. 63-115, 2009.

Leiponen, A. Skills and innovation. International Journal of Industrial Organization, 23(5), p. 303-323, 2005. 
Lewkovicz, Z. \& Kant, J.-D. A multi-agent simulation of a stylized french labor market : emergences at the micro-level. Advances in Complex Systems, 11(2), p. 217-230, 2008.

Lindbeck, A. \& Snower, D.J. The insider-outsider theory of employment and unemployment. Cambridge: MIT Press, 1988.

Mortensen, D. T. \& Pissarides, C. Job creation and job destruction in the theory of unemployment. Review of Economic studies, 61(3), p. 397-415, 1994.

Neugart, M. Labor market policy evaluation with ACE. Journal of Economic Behavior and Organization, 67(2), p. 418-430, 2008.

OECD. Oecd economic outlook. Rapport Technique Volume 2011, Issue 1, OECD, 2011.

Omicini, A., Ricci, A., \& Viroli, M. Artifacts in the A\&A meta-model for multi-agent systems. Autonomous Agents and Multi-Agent Systems, 17(3), p. 432-456, Décembre 2008.

Phelps, E. Microfoundations of employment and inflation theory. Macmillan, London, 1970.

Pissarides, C. Labour Market Adjustment: Microeconomic Foundations of Short-run Neoclassical and Keynesian Dynamics. Cambridge University Press, 1976.

Pissarides, C. Equilibrium unemployment theory. Blackwell, Oxford, 1990.

Pissarides, C. The unemployment volatility puzzle: is wage stickiness the answer. Econometrica, 77(5), p. 1339-1369, 2009.

Richiardi, M. Toward a non-equilibrium unemployment theory. Computational Economics, 27, p. 135-160, 2006.

Salop, S. C. Monopolistic competition with outside goods. The Bell Journal of Economics, page 141-156, 1979.

Service-Public.fr. Allocation d'aide au retour à l'emploi (ARE) : montant et versement. 2011.

Simon, H. A. A behavioral model of rational choice. The Quarterly Journal of Economics, 69(1), p. 99-118, 1955.

Simon, H. A. Rational choice and the structure of the environment. Psychological Review, 63(2), p. 129-138, 1956.

Stigler, G. J. Information in the labor market. The Journal of Political Economy, 70(5), p. 94-105, 1962.

Tassier, T. \& Menczer, F. Emerging small-world referral networks in evolutionary labor markets. Evolutionary Computation, IEEE Transactions on, 5(5), p. 482-492, 2001. 